\title{
Finding What Fits: Breadth of Participation at the Transition to High School Mitigates
}

\author{
Declines in Self-Concept
}

\author{
+*Kathryn L. Modecki, PhD \\ School of Applied Psychology \& Menzies Health Institute of Queensland, Griffith \\ University, Mt. Gravatt Australia \\ School of Psychology \& Exercise Science, Murdoch University, Australia \\ *Corey Blomfield Neira, PhD
}

School of Psychology \& Exercise Science, Murdoch University, Australia

\author{
Bonnie L. Barber, PhD
} School of Applied Psychology \& Menzies Health Institute of Queensland, Griffith
University, Gold Coast Australia

*first and second authors contributed equally to the study +corresponding author

\section{Developmental Psychology, 54(6), 1954-1970}

CAmerican Psychological Association, [2018]. This paper is not the copy of record and may not exactly replicate the authoritative document published in the APA journal. Please do not copy or cite without author's permission. The final article is available, upon publication, at: DOI: 10.1037/dev0000570

Note. Special thanks to four anonymous reviewers whose feedback helpfully contributed to the final study. Thanks also to Megan Duvenage and Bep Uink for useful comments on the final manuscript and to Melanie Zimmer-Gembeck for feedback on analyses. Many thanks to Jacquelynne Eccles, Lynette Vernon, and Catherine Drane for their insights in relation to this manuscript and to the wider YAPS-WA team, including Bree Abbott and Stuart Watson for their intellectual input and contributions to data collection. Thanks also to the Murdoch University School of Psychology \& Exercise Science Research Capacity Fund which supported the first and second authors' joint work on the manuscript. Portions of this research originated as part of the PhD of the second author, at Murdoch University. The Youth Activity Participation Study of Western Australia (YAPSWA) has been supported through three grants under Australian Research Council's Discovery Projects funding scheme: DP0774125 and DP1095791 to Bonnie Barber and Jacquelynne Eccles, and DP130104670 to Bonnie Barber, Kathryn Modecki, and Jacquelynne Eccles. We would like to thank the high school principals, their staff, and the students who participated in the YAPS-WA study. 


\begin{abstract}
Extracurricular activities represent a key setting for prevention and promoting positive youth development. However, to date, a crucial aspect of activity participation-activity breadth (participation in a variety of extracurricular settings) — has been largely overlooked as a resource for bolstering adolescents' long-term adjustment, especially in the development of self-concept. To examine the long-term psychosocial effects of involvement in multiple extracurricular settings, this study modelled latent trajectories of general, social, and academic self-concept and intensity and breadth of participation across five years (Grades 8-

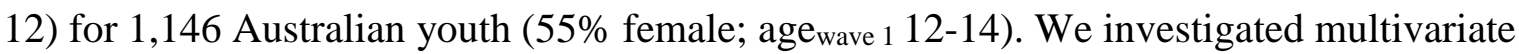
change in self-concept and in breadth of participation, while concurrently modelling intensity of participation. Self-concept and breadth followed a quadratic trajectory, declining across the early-to-middle high school years and increasing during the final high school years. Intensity was also quadratic, but increased early on, followed by steep declines. Notably (and controlling for intensity), wider breadth of participation at the transition to high school predicted less-steep declines in general and academic self-concept across the early-to-middle high school years. Findings support the potential for breadth of participation as a promising avenue for stimulating adolescents' adjustment, by buffering against early declines in their views of self.
\end{abstract}

Keywords: Self-Concept; Trajectory; Extracurricular Participation; Positive Youth Development; Prevention; Breadth of Participation 


\section{Finding What Fits: Breadth of Participation at the Transition to High School Mitigates \\ Declines in Self-Concept.}

Extracurricular activities are an important setting for both prevention and positive youth development, as they help mitigate risky behaviour and assist in building positive norms, prosocial attributes, and constructive views of the self (Catalano et al., 2002; Eccles, Barber, \& Stone, \& Hunt, 2003; McCabe, Modecki \& Barber, 2016; Williamson, Modecki, \& Guerra, 2015). In an effort to delineate characteristics of settings associated with such positive effects, experts have enumerated a range of features that are afforded by exposure to various sport and activity settings. These features appear to facilitate positive development, such as opportunities for building self-efficacy (Eccles \& Gootman, 2002). Critically, these and other scholars highlight that no single setting is anticipated to provide optimal experiences across these promotive features, but rather exposure to a healthy balance of positive setting characteristics is what facilitates youths' competencies (Mahoney, Larson, Eccles, \& Lord, 2005).

Although it is well documented that participation in organized activities is widely beneficial for youth (e.g. Busseri \& Rose-Krasnor, 2009; 2010; Farb \& Matjasko, 2012), it is also the case that different types of extracurricular activities offer youth distinct social environments (Modecki, Barber, \& Eccles, 2014). Likewise, participation in different types of activities has been linked to distinct outcomes (Blomfield \& Barber, 2009). That is, the positive experiences that occur during participation have been shown to vary across separate types of activities (Hansen et al., 2003; Larson et al., 2006). Thus, youth involvement in multiple structured activity contexts, often referred to as activity breadth, may serve as part of a critical foundation for bolstering youths' trajectories (Denault \& Poulin, 2009).

Surprisingly, we know relatively little about the long-term effects of youths' involvement in multiple activity contexts (Simpkins, Eccles, \& Becnel, 2008), especially 
when considering effects of time spent in these activities. In theory, youths' participation in a wide breadth of activities requires them to navigate varied goals, social relationships, and demands (Larson et al., 2006), and in so doing, catalyses their psychosocial development. Illustratively, each activity in which a youth participates exposes him or her to distinct interpersonal experiences and thus discrete development opportunities (Hansen et al., 2003). Because experiences vary among each activity (Larson et al., 2006), by spending time in a variety of contexts, youth are more likely to find their "fit," encounter constructive identity experiences, and undergo more positive development overall (Eccles et al., 1993). As a result, when youth explore a variety of settings, each with a unique ecology, they are provided with further opportunities for cultivating psychosocial competencies, including self-concept.

Self-concept, or youths' perceptions of their own abilities, characterizes how youth think of themselves and what they are capable of. Not surprisingly, it is also a mediator of numerous positive outcomes, including perseverance, achievement, and overall well-being (Marsh \& O’Mara, 2008). A major driver of learning and motivation, self-concept is cultivated through affirmative experiences and feedback from others (Bracken \& Lamprecht, 2003). These and other positive experiences may also stem from exposure to a variety of activities (Hansen et al., 2003). In fact, self-concept should be an especially salient outcome of time spent in a variety of settings during adolescence, as a developmental period when youth consolidate internal representations of who they are, and peer appraisals take on an outsized significance (Blakely-McLure \& Ostrov, 2016). Illustratively, successful participation in a given setting (e.g. school band) can enhance adolescents' attributions for success (e.g. "If I practice, I will get better.") contributing to youths' positive regard for salient skills (e.g. preparation and rehearsal) and persistence in relevant tasks (e.g. perseverance through challenge). Further, successful participation might also elicit positive experiences with peers and encouraging feedback from adult-leaders. These and other 
successful experiences, which can stem from positive encounters within extracurricular settings, will arguably bolster positive views of self across varied domains.

Although enhanced self-concept and adolescents' varied activity exploration are linked, scholars have yet to consider how broad engagement at the transition to high school might contribute to adolescents' shifting self-attitudes across the high school years. That is, it is unclear whether adolescents' early breadth of participation at the transition to high school relates to changes in self-concept, in general, or to specific self-concept dimensions (e.g. academic, social). Moreover, research on the potential benefits of participation breadth has inconsistently accounted for key participation dimensions, such as intensity (i.e. hours spent across activities on a weekly basis). Given that development of identity is arguably a fundamental "project" of adolescence (Blomfield \& Barber, 2009), exploring how early breadth might facilitate development of adolescents' self-views may be especially constructive.

\section{Development of Self-Concept- Academic, Social, and General}

Adolescents' varied activity exploration should enhance their self-concept, as selfperceptions are shaped through interactions and experiences in varying contexts (Marsh \& O’Mara, 2008). Through interpersonal relationships, experiences, and interactions with their wider environment, adolescents learn about who they are and what they can do, thus helping form healthy internal self-representations (Harter, 1999). Therefore, a variety of engagement experiences likely provides youth with ample opportunities to gain positive insights about themselves and their abilities across varied domains. As a result of these unique learning opportunities, diverse activity participation may lead to enhancements in self-concept.

Self-concept serves as an over-arching framework that guides adolescents' choices, stimulates opportunities, and regulates behaviour. More specifically, self-concept includes multiple dimensions such as social relationships, academic performance, and behavioral 
abilities (Harter, 1999). These domains are associated with corresponding behaviors and motivations, and contribute to individuals' overall evaluative opinion of themselves, or general self-worth. Academic and social self-concept, in particular, are tied to essential maturational tasks during the high school years; whereas the global dimension of general self-worth can be considered integral for development more broadly (Blomfield \& Barber, 2009). Breadth of engagement should afford multiple building grounds for competencies, which in turn likely translates to positive views of self in each of the following domains.

First, collecting a variety of experiences in structured settings beyond the classroom may help to enhance views of fit and competence in academic spheres. For instance, youth learn to succeed when they try hard, cope with competing demands across diverse settings, and persist in the face of varied challenges. These experiences can strengthen views of their own fit at school and ability to manage academic demands. Academic self-concept, in turn, is integral to development of academic motivation, playing a pivotal role in school belonging and engagement, achievement, and educational aspirations and goals (Musu-Gillette, Wigfield, Harring, \& Eccles, 2015).

Second, social self-concept is likewise critical to adolescents' development and, as with academic self-concept, results from attributions, experiences with others, and interactions with the larger social world (Harter, 1999). Adolescents who engage in multiple activities encounter numerous group membership opportunities, including trying out new social skills and becoming a member of diverse peer groups. For instance, through diverse participation, an adolescent might assume a leadership role, engage with prosocial adults, or learn to be a positive team member. Consequently, adolescents who take part in a spectrum of these activities should be better equipped to form healthy self-concepts of social relations.

Third, general self-worth is characterized by a global positive sense of the self, and in this context taps adolescents' opinions of their competencies (Blomfield \& Barber, 2011; 
Harter, 1999). General self-worth may also be bolstered through breadth of engagement, as adolescents who are exposed to a variety of activities are more likely to identify and build upon personal strengths. Through this process, youth should better connect to those arenas within which they might perform well and build pride from their accomplishments.

These three aspects of self-concept are best tracked independently, as each domain can follow a different developmental course. Although self-concept generally declines on average across adolescence, there is variability both across domains and between adolescents (Molloy, Ram, \& Gest, 2011). In general, declining patterns of self-concept are found across many areas (Fredricks \& Eccles, 2002, mathematics, sport; Jacobs et al., 2002, mathematics, language arts, sports; Nagy et al., 2010, mathematics). However some research suggests the opposite, showing increases in certain dimensions of self-concept (Molloy et al., 2011, academic, social). Thus, sketching the independent maturational course of each of these domains can provide valuable insight regarding development of distinct aspects of the self.

\section{Charting Adolescent Self-Concept and Timing of Breadth}

Self-concept can be considered to form the foundation of our internal representations of self, and so charting the maturation of these features across the teenage years may be especially valuable for our understanding of adolescent development. Further, as selfperceptions provide a lens for synthesizing self-knowledge, developmental shifts in these perceptions could have enduring effects. Specifically, when adolescents' self-concept dips or de-stabilizes, this in turn can ripple-on to corresponding negative outcomes in a variety of life-domains (Marsh \& O’Mara, 2008).

The benefits of a wider breadth of participation should be particularly potent during the developmental period of early adolescence. This is because the 'fit' that youth experience through extracurricular activity participation may help counteract a concurrent sense of uncertainty commonly experienced during this phase. That is, engaging in a breadth of 
activities, especially at the entry to high school, when manifold academic, extracurricular, and social opportunities are available, should help mitigate declines in self-concept across the high school years (e.g., Marsh \& Yeung, 1998). Moreover, the longer term effects of early breadth may be especially pronounced depending on the timing of this transition. For instance, some educational settings transition to high school earlier than others (e.g. before $9^{\text {th }}$ grade) and thus any persisting effects of early breadth may be more evident. More specially, in the context of the current study, youth transition to high school in eighth grade, where they remain for five years in total, thus providing a relatively expansive developmental lens.

\section{Pairing Self-Concept with Breadth of Participation}

Adolescents' exploration of various contexts and the development of identity should be related, as trying out different settings to discover those that best fit their abilities and motivations may pave the way for optimal outcomes. As suggested by stage-environment fit theory, psychological benefits and consequently more positive developmental trajectories occur when there is congruence between developmental and environmental needs (Eccles et al., 1993). As a result, voluntary involvement in a widef breadth of activity types should facilitate a better 'fit' to youths' skills, personality, and talent (Eccles \& Barber, 1999).

Our claim that breadth of participation might facilitate "fit" and thus buffer against declines in self-concept brings with it a complimentary possibility. That is, breadth might influence adolescent self-concept in two opposing ways. One way, as described above, when an adolescent discovers a good "fit," is to validate identity and facilitate positive social feedback. Another possibility, though, is that an adolescent engages in activities that are a poor fit with their personality or skill-set. Or, a youth might participate in activities that include hostile peers, negating affirmative social appraisals that typically stem from participation. Illustratively, some research highlights links between extracurricular involvement and externalizing behaviors, including bullying (Farmer et al., 2003). Thus, if 
contexts are problematic, or otherwise not well-suited to adolescents' strengths and values ${ }^{1}$, goodness-of-fit might equally connote a dampening effect.

\section{Operationalizing Participation}

Although we conceptualize extracurricular activities as useful for galvanizing youths' positive self-views, only a handful of studies have explored adolescents' breadth of participation. Foundational work has linked broad participation in an array of activities to diminished involvement in risk behaviour, greater civic engagement, higher levels of successful development, better academic outcomes, and more positive friendship characteristics (e.g. Busseri et al., 2006; Fredricks, 2012). Even fewer studies have examined how breadth changes over time, however this work suggest that early breadth plays a role in later positive outcomes, even after accounting for normative declines in breadth across multiple years (Grades 7-11; Denault \& Poulin, 2009). For example, Denault and Poulin showed that wide breadth of participation during early adolescence was the chief predictor of later academic orientation and civic development, above and beyond subsequent change in breadth over time. When both changes in breadth and intensity were examined together, neither made unique contributions to later outcomes, suggesting a degree of shared variance.

Breadth and intensity of participation clearly overlap, however in contrast to breadth, intensity provides a time-based picture of an adolescents' involvement. Indeed, cultivation of identity and positive social judgements require the provision of time, and intensity likely reflects youths' investment in and prioritizing of extracurricular activities (Busseri \& Rose-Krasnor, 2009). Further, intensity may help shed light on potential repercussions from overscheduling of activities (Bohnert, Fredricks, \& Randall, 2010). That is, some limited

\footnotetext{
${ }^{1}$ We thank the Editor and several anonymous reviewers for suggesting this point.
} 
evidence suggests that over-scheduling can contribute to negative outcomes, likely as a reflection of youth stress (Fredricks, 2012).

Although a minimum intensity of involvement may be necessary for benefits of breadth to accrue (Gestsdóttir \& Lerner, 2007), here we consider breadth of participation to be especially beneficial to self-concept. Breadth is not characterized by the number of activities in which an adolescent participates. Rather, it refers to the variety of activities in which a youth is involved. Illustratively, an adolescent involved in three different sports (e.g. soccer, basketball, and football), receives a breadth score of one, whereas an adolescent involved in two different activity types, such as sports (e.g., soccer) and performing arts (e.g., drama club), receives a score of two. In this way, diverse experiences are captured (Blomfield \& Barber, 2009). That said, intensity likely helps to channel specific developmental experiences, so that youth acquire the skills afforded by each specific setting.

\section{The Present Study}

The present study fills two critical gaps in the literature. First, prior research on developmental self-concept trajectories has generally focused on specific academic selfconcept domains (e.g. self-beliefs around mathematics performance and ability). We build on relevant and continuing interest in developmental fluctuations in adolescents' views of self. Specifically, we chart within-person change in three self-concept arenas-academic and social self-concept, and general self-worth — across five years of adolescence (i.e.; at the entry to high school in $8^{\text {th }}$ grade, where youth remain until 12th grade graduation).

Second, previous work has under-explored the long-term impact of breadth of participation for bolstering youths' psychosocial adjustment, including self-concept. We speak to this gap in understanding and pair developmental change in each self-concept dimension with developmental change in participation breadth, while controlling for change in participation intensity. 
Because exposure to a breadth of settings may be especially influential at the beginning of high school, when adolescents tend to participate in a range of activities, we specify early breadth as a predictor of changing self-concept over time. We also allow for the possibility that high early self-concept might drive youth to maintain involvement in a broad range of extracurricular settings over time (e.g. selection effects) and further specify early self-concept as predicting change in breadth.

Finally, we consider potential selection effects by controlling for key covariates of gender, SES, early depressed mood, and early self-esteem. Specifically, gender gaps have been shown for youth self-concept and boys often start higher than girls (though no differences were found in rate of decline; Jacobs et al., 2002). Additionally, youth from higher SES backgrounds tend to experience higher levels of self-concept (Muijs, 1997); and depressed mood can predict deteriorations in self-competence (Cole, Martin, \& Powers, 1997); finally, decreases in self-esteem can track reductions in self-concept and interest in activities (Wigfield \& Eccles, 1994).

\section{Method}

\section{Participants and Procedure}

The sample consisted of adolescents from 39 high schools involved in the Youth Activity Participation study (YAPS, see Modecki, Barber, \& Vernon, 2013; Vernon, Modecki \& Barber 2018 for descriptions of longitudinal study) of adolescents' experiences and wellbeing. Participating high schools were selected to represent the four metropolitan school districts and five of the six regional school districts across Western Australia. Within each district the number of schools recruited and the type of schools selected (government $n=21$; non-government $n=18$ ), was determined by district high school enrolment rates. In order to include a range of socioeconomic statuses, the Index of Community Socio-Educational Advantage (ICSEA) was used for school recruitment (Blomfield \& Barber, 2011). The 
ICSEA is a school-level SES measure, which places schools on a numerical scale and indicates their comparative socioeconomic advantage based on the education, occupation, income, ethnicity, and single parent status of each student's household (ACARA, 2010). Schools in our sample ranged between two standard deviations above and below the state mean. Spearman's rho coefficient indicated a significant positive monotonic association between school SES rank and participants' breadth of participation $\left(\mathrm{rs}_{w 1}=.32, p<.001 ; \mathrm{rs}_{w 2}\right.$ $\left.=.27, p<.001 ; \mathrm{rs}_{w 3}=.29, p<.001 ; \mathrm{rs}_{w 4}=.23, p<.001 ; \mathrm{rs}_{w 5}=.1, p=.015\right)$.

The study had ethical approval for the Youth Activity Participation Study from the Murdoch University Human Research Ethics Committee, Education Department, and Catholic Education Office, approval \# 2007/029, \# 2010/071, \# 2013/047. Active informed parent and student consent were required. The survey took approximately 40 minutes and was conducted using a mobile computer lab. Students were informed that their participation was voluntary, and that their responses would remain confidential.

The study included 1,146 adolescents (55.3\% female), Mage $_{w 1}=13.29$ (range: $12.42-$ 14.59). Forty-three percent of youth were drawn from lower socioeconomic status schools. Of the sample, $81.6 \%$ were Caucasian, $7.5 \%$ Asian, $1.6 \%$ Aboriginal and Torres Strait Islander, $1.5 \%$ African, or $4.3 \%$ other (e.g. Middle Eastern); $3.5 \%$ did not nominate ethnicity. Students participated in the first cohort of YAPS during the first five years of annual data collection. YAPS consisted of two major data collection cohorts. The current study focuses on the first cohort of students whom completed the survey at least twice ${ }^{2}$; the study began in $8^{\text {th }}$ grade and followed youth over five years of high school. For these waves, hand-coded breadth data were available for activity participation (see Measures section). The mode for participation was five waves and $82.6 \%$ of youth participated in three or more waves. We

\footnotetext{
2183 students were excluded because they participated in only one of five waves of data collection. All analyses were re-run with data from these youth included and study results were substantively the same.
} 
recruited schools by contacting school principals, and maintained regular communication over the years. We recruited students through assemblies and in-class recruiting strategies. Students who returned parent consent forms and who completed assent forms took part in the study $\left(\right.$ Retention Wave $2=91.4 \%$, Retention Wave $_{3}=89 \%$, Retention Wave $4=66 \%$, Retention Wave $_{5}=74 \%$ ). Logit regression analyses indicated that, in comparison to participants who dropped-out by the final wave, participants with data across all waves were more likely to be female, have higher SES, report greater ECA activities and breadth, and higher academic self-concept at wave 1 . However the amount of explained variance in the overall equation was quite small, as indicated by pseudo $\mathrm{R}^{2}$ for the overall equation $=.09$ (see Miller \& Wright, 1995; see Supplementary Section for a detailed discussion of attrition and treatment of missing data).We assessed youth during the same time frame annually, at the end of the year. The annual survey asked youth to reflect on their participation across the year.

\section{Measures}

In 8th grade participants reported their gender (females=0; males=1) and ethnicity (Caucasian=0; all other ethnicities $=1$ ). In addition, self-esteem and depressed mood in $8^{\text {th }}$ grade were included as covariates in order to control for potential selection effects. (Details provided in the Supplementary Section). In 8 th- $12^{\text {th }}$ grade, participants responded to measures of extracurricular activity participation in and out of school, as well as assessments of general self-worth, and academic and social self-concept. These were the only self-concept measures included in the study, and our exploration is limited to these three dimensions.

Table 1 includes the means and standard deviations for study measures.

Participation in extracurricular activities. Participation in structured/organized extracurricular activities (ECA) was assessed in waves 1 through 5 (Grades 8, 9, 10, 11 and 12) by providing students with a list of 30 sports and 24 non-sport structured extracurricular activities with space at the end of each list to add other structured activities. The lists were 
based on previous structured extracurricular activity research (Eccles \& Barber 1999; Feldman \& Matjasko 2007) and Australian pilot testing (as described in Blomfield \& Barber, 2009). Participants were asked to indicate all of the structured/organized extracurricular activities that they were involved in during the school year outside of school hours, both in and out of school and to report the number of hours per week that they participated in each activity.

ECA intensity. Consistent with many studies in the field (e.g. Denault \& Poulin, 2009) intensity of participation was the sum number of hours an adolescent reported participating in outside of school hours for each extracurricular activity per week, at each wave. Following Busseri et al. (2006), we used an aggregate intensity score. This included all hours spent across all activities, in order to assess the entirety of each youth's involvement and the impact of this involvement. Intensity scores were winsorized so that 30 hours was the maximum possible hours. Visual inspection of the data suggested distributions were unimodal.

ECA breadth. Breadth of extracurricular activity participation was created for each wave based on previous work (Eccles \& Barber, 1999), by categorizing all of the extracurricular activities into 6 activity types: Sports, performance $\&$ fine arts, academic clubs, recreation clubs, service activities, and faith-based clubs. The number and type of activity categories selected was based on published research (Bohnert, Martin, \& Garber, 2007; Denault \& Poulin, 2009; Larson et al., 2006), as well as studies highlighting unique developmental experiences afforded by these categories (Hansen, Larson, \& Dworkin, 2003; Larson et al., 2006). Our coding followed previous work (Eccles \& Baber, 1999), and after pilot testing included an additional category (recreation club). Following categorization, a sum was computed to reflect the number of different extracurricular activity types in which an adolescent participated outside of school hours. At each wave, participation breadth 
ranged from 0-5 activity types; visual inspection of the data indicated distributions were unimodal (median and mode at each wave $=1$ ) and relatively normal. Validity checks indicated that breadth was correlated with, but distinct from, other conceptualizations of activity types (Table S1). Descriptive percentages of youth participation are also provided in Table S2 and illustrative examples of activities in each breadth category are in Table S3.

General self-worth. The measure of general self-worth was adapted from existing scales (Marsh,1992b, c, d), and has shown good validity in previous work (Blomfield \& Barber, 2009; 2011). Importantly, a body of research supports the distinction between general self-concept and more specific self-concept facets described below (e.g. O'Mara, Marsh, Craven, \& Debus, 2006). The measure consists of 4 items (e.g., “A lot of things about me are good') assessed on a six-point Likert scale (1: False, not like me at all; 6: True, this describes me very well). The scale had good reliability across the five waves (Cronbach's $\left.\alpha_{\mathrm{w} 1}=.82 ; \alpha_{\mathrm{w} 2}=.85 ; \alpha_{\mathrm{w} 3}=.87 ; \alpha_{\mathrm{w} 4}=.84 ; \alpha_{\mathrm{w} 5}=.82\right)$.

Social self-concept. Social self-concept was likewise adapted from previous research (Marsh, 1992b, c, d), and has been shown to be valid (Blomfield \& Barber, 2009; 2011). The measure was based on three items, including "I am very good at making friends." Items were assessed on a six-point Likert scale (1: False, not like me at all; 6: True, this describes me very well). Social self-concept was shown to be reliable across each of the five waves $\left(\alpha_{\mathrm{w} 1}=.75 ; \alpha_{\mathrm{w} 2}=.75 ; \alpha_{\mathrm{w} 3}=.75 ; \alpha_{\mathrm{w} 4}=.77 ; \alpha_{\mathrm{w} 5}=.73\right)$.

Academic self-concept. The academic self-concept measure was adapted from existing scales (Marsh 1992b, c, d) and has been shown to be valid in previous work (Blomfield \& Barber, 2009; 2011). The scale consisted of three items including: "I have the ability to be good at most school subjects if I try," all measured on a six-point Likert scale (1: False, not like me at all; 6: True, this describes me very well). The scale evidenced good 
reliability across all waves of the study (Cronbach's $\alpha_{\mathrm{w} 1}=.79 ; \alpha_{\mathrm{w} 2}=.81 ; \alpha_{\mathrm{w} 3}=.82 ; \alpha_{\mathrm{w} 4}=.81$; $\left.\alpha_{w 5}=.77\right)$.

\section{Analysis Strategy.}

Although inherent to longitudinal studies, given our missing data we ran a number of sensitivity tests of our analyses. First, we used Full Information Maximum Likelihood Estimation (FIML; Yuan \& Bentler, 2000) in Mplus (Muthén \& Muthén, 1998-2012) in all models reported here. Second, we included IPW's (Miller \& Wright, 1995) within our final models, and results were the same. Third, we re-ran models using Multiple Imputation (MI), which included auxiliary variables that were not part of our analytical model when imputing. Again, results were substantively similar.

Analyses proceeded in a series of three steps. First, a series of individual latent growth curve models (LGC) were run via structural equation modelling to assess the best fitting form of each construct (general self-worth, academic self-concept, social self-concept, ECA intensity and ECA breadth) ${ }^{3}$. Second, the associations between the ECA breadth trajectory and each self-concept trajectory were tested using separate parallel process models. Third, the associations between the ECA breadth trajectory and each self-concept trajectory were tested net of ECA intensity trajectories, using separate multivariate growth curve models (Figure S1 provides a schematic) $)^{4}$. These models simultaneously regressed the linear and quadratic slope of self-concept on the intercepts of intensity and breadth. This allowed for a test of whether early breadth predicted change in self-concept, controlling for early intensity and subsequent

\footnotetext{
${ }^{3}$ Results testing SES and gender differences in the covariance structure of latent growth parameters are shown within the Supplementary Section.

${ }^{4}$ Results testing invariance across SES gender for the multivariate relations between self-concept, breadth, and intensity are provided in the Supplementary Section, and show that constraining intercept, linear slope and quadratic slope correlations by SES or by gender did not lead to significant reductions in fit.
} 
changes in intensity. These models also allowed for simultaneous linked associations between intercepts, linear slopes, and quadratic slopes between all three constructs ${ }^{5}$.

In all conditional models, gender, ethnicity, SES, and early self-esteem and depressed mood were included as predictors of intercepts and linear and quadratic slopes to account for time-invariant effects. Continuous covariates were grand-mean centered, and conditional model values represent estimates for trajectories at the mean of each predictor (Curran, Bauer, \& Willoughby, 2004). Interpretations of the effects of covariates in the conditional models were based on plotting of the adjusted estimated means. All analyses were run in Mplus, version 7.0 (Muthén \& Muthén, 1998-2012).

\section{Results}

\section{Descriptive Statistics}

Means, standard deviations, and correlations among study variables are presented in Table 1. General self-worth and social and academic self-concept were positively moderately correlated at each time point; the strength of association between these variables was stronger at the same point of measurement than across waves. Breadth of participation was consistently and positively associated with general self-worth and social and academic selfconcepts at each wave (with the exception of Grade 12 breadth and Grade 8 social selfconcept), though effect-sizes were small.

\section{Latent Growth Curve Models}

Preliminary latent growth models (LGM) examined overall patterns of change for each outcome from Grades 8 to 12 . The best-fitting unconditional model was determined through nested model tests. Model fit was evaluated using chi-square, the root mean square

\footnotetext{
${ }^{5}$ In supplementary analyses, we tested for reliability of multivariate growth curve findings, running autoregressive cross-lag panel models (Figures S2, S3, and S4). Though models fit the data relatively poorly, results followed general conclusions discussed below.
} 
error of approximation (RMSEA), standardized root mean squared residual (SRMR) and the comparative fit index (CFI). Values above .95 for the CFI, below .06 for the RMSEA, and below .08 for the SRMR indicate acceptable fit (Hu \& Bentler, 1999).

Average Trajectories of Self-Concept, Breadth, and Intensity. Preliminary LGM examined overall patterns of change for each outcome from Grades 8 to 12 . These models centered time on the first assessment (W1) and specified intervals of 1 (one year) between each time point. Nested model comparisons indicated that each construct followed quadratic, rather than linear trajectories of change (Table S4). Further, for each self-concept construct and breadth, model comparisons indicated that freeing time residual variances resulted in best model fit. Table 2 describes base models (Model 1) and models with time invariant predictors (Model 2) for general self-worth, social and academic self-concept. Table 3 describes base (Model 1) and time invariant predictor (Model 2) models for ECA breadth and intensity. Standardized coefficients are provided in bold, and can be interpreted in terms of effect-size (Kline, 2011). As shown, beta weights were generally small (.10) to moderate (.30) sized, and no key B value in the study reached a large effect (.50).

General self-worth. Beginning on the far left of Table 2, parameters are presented for the unconditional model (Model 1) for general self-worth. The mean reported general selfworth score in Grade 8 (intercept) was 4.59 and there was a significant average decrease in general self-worth (-.16) across early to mid-adolescence as indicated by the linear slope, with the subsequent rate of decline reducing (quadratic slope $=.03$ ) and a slight uptick in general self-worth in late adolescence. Significant variation was found for the intercept and linear and quadratic slope. In the conditional univariate model (Model 2) females had higher general self-worth than males in Grade 8. There also was a significant effect for gender on the linear and quadric slope. Female adolescents reported declines, on average, in general self-worth in early to mid-adolescence followed by a levelling-off later on; whereas male 
adolescents' reports of general self-worth were relatively stable over time. Further, high SES youth remained relatively stable in general self-worth over time, whereas low SES showed early declines (predicting linear slope $=.01$ ). Youth high in early self-esteem had higher Grade 8 general self-worth (intercept), but showed gradual (significant) declines early on (predicting linear slope $=-.20$ ), which then stabilized (predicting quadratic slope $=.03$ ); whereas youth low in self-esteem remained relatively low in general self-worth across time. Finally, youth low in depression remained relatively stable in their general self-worth across time, where youth high in depression showed early declines (predicting linear slope $=.12$ ), followed by levelling off (predicting quadratic slope $=.03$ ).

Social self-concept. Further right on Table 2, values for the unconditional model of social self-concept (Model 1) show that the average level of social self-concept in Grade 8 was 4.67 (intercept). Across early to mid-adolescence there was significant decline in social self-concept (linear slope $=-.12$ ), but rate of decline levelled off across mid- to late adolescence (quadratic slope $=.02$ ). There was also significant variation in the intercept and linear and quadratic slopes. In the conditional model (Model 2), females had higher social self-concept than males and ethnic minority youth had higher levels of social self-concept in Grade 8 than Caucasian youth (intercept). Youth low in early depressed mood also had higher social self-concept relative to those high in depressed mood. Youth high in early self-esteem were also high in Grade 8 social self-concept (intercept), although these youth underwent more rapid declines in social self-concept cross the early high school years (predicting linear slope $=-.17$ ), followed by stability later on (predicting quadratic slope $=.03$ )

Academic self-concept. Average academic self-concept score in Grade 8 was 4.66. Academic self-concept declined (-.19) across early to mid-adolescence, with the rate of decline slowing and a slight upturn in academic self-concept in late adolescence (quadratic slope $=.03 ;$ Table 2, Model 1). The intercept and linear and quadratic slope all had 
significant variation. In the conditional model, higher SES was associated with higher Grade 8 academic self-concept (intercept). There were also effects for gender on both the linear and quadratic slopes. Male adolescents were relatively stable in their academic self-concept over the five years; whereas female adolescents reported declines in early to mid-adolescence, followed by a slight up-tick in late adolescence. Further, too, youth low in depressed mood were relatively stable in their academic self-concept over time; whereas youth high in depressed mood showed declines across the early high school years (predicting linear slope $=$ -.12 ), followed by a slight up-tick during later years (predicting quadratic slope $=.02$ ). In a fairly similar pattern, youth low in early self-esteem tended to remain stably low in academic self-concept over time; whereas youth high in early self-esteem had higher Grade 8 academic self-concept (predicting intercept $=.50$ ). Although youth high in early self-esteem stayed highest in academic self-concept over-time, they showed early declines (predicting linear slope $=-.18$ ) followed by a levelling-off later on (predicting quadratic slope $=.03$ )

ECA breadth. On the left side of Table 3 values are reported for ECA breadth. Overall, there were non-significant decreases in breadth across early high school (linear slope $=-.03$ ) followed by steeper, significant declines in breadth in the later years (quadratic slope $=-.02$ ). The intercept had significant variation, thought the linear and quadratic slopes did not. That said, lack of significant slope variation does not preclude testing of conditional effects and Model 2 reports the effects for the breadth model with the addition of covariates. There were significant effects for gender, SES, and early self-esteem on ECA breadth in Grade 8 (intercept). Male adolescents reported narrower breadth in Grade 8 than females; higher SES youth and youth with high early self-esteem reported greater breadth in Grade 8.

ECA intensity. On the right of Table 3 values are reported for ECA intensity. There were significant increases in intensity across early high school (linear slope $=1.37$ ) followed by significant declines in the later years (quadratic slope $=-.48$ ). The intercept, linear, and 
quadratic slopes all had significant variation. Model 2 shows the effects of the covariates. There were significant effects for gender, ethnicity, SES, and early self-esteem on ECA intensity in Grade 8 (intercept). Male adolescents reported greater intensity in Grade 8 than females; Caucasian youth reported greater intensity than ethnic-minority youth. Further, high SES youth and youth with higher self-esteem reported higher intensity in Grade 8.

\section{Parallel Trajectories of Self-Concept with ECA Breadth and ECA Intensity.}

Next, we paired each self-concept trajectory with the ECA breadth trajectory to assess the dynamic and possible reciprocal relations between self-concept and breadth. We also paired each self-concept trajectory with the ECA intensity trajectory, in order to provide a sense of associations with self-concept, independent of other ECA dimensions. For example, considering parallel process models with breadth, we regressed the linear and quadratic slope of self-concept onto the intercept of breadth. A significant path would indicate that $8^{\text {th }}$ grade breadth is associated with changes in self-concept over time. Because it is plausible that early self-concept could also affect changes in breadth, in these models the linear and quadratic slope of breadth were also regressed onto the intercept of self-concept. Further, correlations were specified between the residuals of the intercepts, linear slopes, and quadratic slopes of ECA breadth and each self-concept construct. As described in Table S5; early intensity did not predict change in any self-concept dimension. However, early general self-worth was associated with trend-level changes in ECA intensity (positive effect on linear and negative effect on quadratic slope). As shown in Table S6 findings also indicated effects of early breadth on changes in general self-concept (characterized in Figures 1A and 1B, positive effect on linear and negative effect on quadratic slope), effects of early breadth on changes in academic self-concept (characterized in Figures 1C and 1D, positive effect on linear and negative effects on quadratic slope), and trend-level, positive effects of ECA breadth on linear increases in social self-concept. 
Multivariate Trajectories of Self-Concept and ECA Breadth. Finally, we paired all three relevant trajectories together - self-concept with both ECA intensity and ECA breadth. These models again were specified so that early breadth predicted changes in selfconcept and changes in intensity. Likewise, early intensity was specified to predict changes in self-concept and changes in breadth. Further, early self-concept was specified to predict changes in breadth and intensity. All intercepts, linear slopes, and quadratic slopes were correlated in the models. In accordance with modification indices, residual correlations between manifest indicators of breadth and intensity were also specified at each time-point.

General self-worth multivariate trajectories. Model results pairing general selfworth, ECA breadth, and intensity trajectories are provided in Table 4. Wider eighth Grade breadth of participation (intercept) predicted less steep declines in general self-worth across the early high school years (linear slope, $b=.31$ ). A significant negative effect of early breadth (intercept) on general self-worth on the quadratic slope $(b=-.07)$ indicated that the benefits of wide early breadth on general self-worth were less robust in the later high school years, though this effect did not fully mitigate breadth's positive effects. There were no reciprocal effects of early self-worth on change in ECA breadth. The intercepts, linear, and quadratic slopes of the two processes were not significantly correlated. Notably, early ECA intensity did not predict changes in self-worth; nor did early general self-worth predict changes in intensity. The two intercepts were positively correlated, but neither the linear nor quadratic slopes of intensity and general self-concept were correlated.

Social self-concept multivariate trajectories. Table 5 provides the results of the paired social self-concept, ECA breadth, and ECA intensity model. As shown, there were no significant effects of early breadth on changes in social self-concept (though there was a trend level positive effect on the linear slope $=.20$ ). Nor were there significant effects of early social self-concept on changes in breadth. The intercepts, linear slopes, and quadratic slopes 
of the two processed were not significantly correlated. Further early intensity did not predict changes in social self-concept, nor did early social self-concept predict changes in intensity. Though early intensity and social self-concept were positively correlated, neither the linear nor quadratic slopes of the two processes were associated.

Academic self-concept multivariate trajectories. Results of the paired academic selfconcept, ECA breadth, and ECA intensity trajectory model are provided in Table 6 . Wider early breadth of participation (intercept) predicted less steep declines in academic selfconcept early on (linear slope $=.24$ ), although a "bounce back" effect was evident and breadth intercept was also predictive of later declines in academic self-concept (quadratic slope $=-.06)$. There were no reciprocal effects of early academic self-concept on changes in ECA breadth, and the change factors (linear and quadratic slopes) between the two constructs were not significantly correlated. In this model, the intercepts were positively correlated $(\mathrm{r}=$ $.25)$, indicating that in eighth grade, wider breadth of participation was associated with higher academic self-concept. Notably, early intensity did not predict changes in academic selfconcept, nor did early self-concept predict changes in intensity. Neither the intercepts, linear, nor quadratic slopes between intensity and academic self-concept were correlated.

\section{Discussion}

This study is the first to pair changes in breadth of extracurricular participation with developmental changes in distinct self-concept dimensions across adolescence. In so doing, it provides convincing evidence that participation in a broad array of structured, adult-led activities at the transition to high school helps to scaffold adolescents' emerging views of the self. Breadth of participation at the high school transition (eighth grade), helped mitigate normative declines in general and academic self-concept across the ensuing four years. Findings controlled for parallel changes in intensity and in this case it was breadth of participation which drove self-concept development. Moreover, protective effects of breadth 
were not reciprocal; particularly high (or low) early self-concept did not drive changes in either breadth or intensity. Rather, exposure to a variety of extracurricular settings at the transition to high school seems to provide youth with a broad array of experiences which help to lessen age-typical declines in self-concept. Consequently, enhancing prosocial extracurricular offerings where youth might encounter their constructive identity "fit" may be one promising avenue for promoting healthy psychosocial functioning (Modecki et al., 2014).

\section{Self-Concept Trajectories}

Positive self-concept is vital for stimulating healthy development during adolescence (Eccles et al., 1993) and is linked to improved well-being through young adulthood (Marsh \& O'Mara, 2008; Simpkins et al., 2015; Park, 2003). Across three psychosocial arenasacademic, social, and general self-concept—we found patterns of early decline following the high school transition ( $8^{\text {th }}$ grade), which parallels previous findings from other self-concept domains. Illustratively, Jacobs and colleagues (2002) report declines in sport and math selfconcept across grades 7-12, and Nagy and colleagues (2010) report similar developmental declines as assessed within three different countries. But we also found evidence of up-turns in self-concept during the later high school years; academic and social self-concept and general self-worth followed quadratic trajectories. The three domains showed declines across the early-to-mid high school years, but the rate of decline slowed over time, with slight increases in each during the final years of high school.

It may be the case that our sample benefited from the timing of their developmental transition to high school (here, in $8^{\text {th }}$ grade), and continuation within this same school setting for a total of five years. Such stability may have contributed to adolescents' developmental recovery of self-concept as they re-established social reference groups and "re-shuffled" their investments in various life-domains (Cole et al., 2001). Other Australian research (though cross-sectional) has likewise described a U-shaped curve across the adolescent years (grades 
7-12) for numerous self-concept dimensions (Marsh, 1990). That said, our pattern of steep declines found at the beginning of the transition to high school is also consistent with research on specific self-concept domains (Fredricks \& Eccles, 2002) and highlights potential vulnerabilities in self-system formation during this period. Such vulnerability likely results from intensive psychosocial change youth are experiencing across the transition, in tandem with marked differences between the elementary and high school environments (Wigfield et al., 1991). For example, as youth begin secondary school they encounter disrupted social networks and vastly altered academic expectations. Thus identifying malleable factors which can help buffer against this normative pattern of early decline may be a useful strategy.

\section{Extracurricular Trajectories-Breadth and Intensity}

We posited that exposure to a variety of structured, non-academic settings could be especially helpful in this regard, and so charted within-person change in breadth of participation across five years of high school. In our models, breadth showed a pattern of slight, non-significant decreases across early high school, followed by more significant declines in the later high school years. Moreover, there was non-significant variation within the breadth slopes (linear and quadratic), indicating relatively few individual differences. In a previous study of roughly 300 Canadian youth, breadth showed linear declines across Grades 7-11; (Denault \& Poulin, 2009). Our findings parallel those described in previous research in pointing to declines in the variety of contexts in which youth participate later in high school. However, we find that youth maintain connection to the same relative variety of settings during the early high school years. Thus, during the secondary school transition and across the first few years, youth appear to experiment with a variety of extracurricular settings. However, as they progress through high school and as activities become increasingly specialized, youth narrowed-in on settings in which to dedicate themselves. 
Intensity of participation, here operationalized in terms of total weekly hours in activities, also followed a curvilinear trajectory. But intensity followed an inverted-U, increasing significantly across the early high school years, followed by more rapid declines in the later years. This developmental course parallels findings reported by Denault and Poulin (2009), who likewise found that intensity (total activity hours across the year) followed a quadratic course, increasing early-on and declining thereafter. Unlike breadth, intensity showed significant between-person variability in trajectory change.

\section{Breadth, Intensity, \& Self-Concept Multivariate Process Models}

Self-concept is thought to be largely a product of individuals' experiences with their interpersonal environments (Harter, 1999) and our findings suggest that breadth of participation may be one useful approach for building these psychosocial competencies. Breadth of participation at the transition to high school enhanced self-concept development, even though this effect abated by the later high school years. Thus, this study's major contribution is showing that initial wide breadth of activity participation during early adolescence helps foster early gains in development of general and academic self-concept, gains that help to offset normative declines during this period. Although all three aspects of self-concept underwent declines across the early high school years, wider early breadth mitigated against decreasing general and academic self-concept during this critical initial period. These protective effects emerged in a conservative test of our hypothesis, controlling for subsequent changes in breadth, possible reciprocal effects of early self-concept, as well as simultaneous change in participation intensity. Indeed, adolescents would not necessarily be expected to benefit from a wide participation breadth if they were overcommitted or challenged by managing multiple demands (Bohnert et al., 2010; Fredricks, 2012).

These positive effects of wide early breadth dampened later on, for which there are several potential explanations. First, as touched on earlier, goodness-of-fit also implies a 
competing direction of effect; when breadth of activities are ill-matched with youths' personalities or talents, then engagement might diminish growth. Further, some activities may be more encouraging of psychosocial growth than others. In particular, there have been findings of potential negative effects of sport-participation on youth development (Drane et al., 2017; Farb \& Matjasko, 2012), and undesirable norms or discouraging feedback within settings that are unconstructive might stall development. Second, as youth mature through high school, narrowing of activities to better suit individual strengths could serve to enhance well-being. Thus, narrower participation breadth may be beneficial as youth increasingly hone-in on settings which enhance prosocial views of the self. Third, later dampening may reflect "bounce back" effects, as widely engaged youth come to more closely resemble the average adolescent. Importantly, these later negative effects of breadth — whether associated with youth failing to find their fit, later benefits of narrowing, or simply bouncing-back to average — do not diminish protective early effects of breadth on general and academic selfconcepts. As described in our figures, female and male youth who were high in early breadth remain highest in general and academic self-concept overall. Importantly, too, some declines in self-concept during adolescence appear to be developmentally normative. By delaying these decreases to later in high school, adolescents who engage in an early breadth of activities may be better equipped to offset declines later on (Modecki, 2016).

Unlike general self-worth and academic self-concept, the developmental course of social self-concept was not affected by early breadth. Like other self-concept facets, social self-concept is relative, and positive comparisons with peers in this arena may be more difficult to modify during the teenage years (e.g. O'Mara, et al., 2006). Given that early selfconcept was positively correlated with early intensity, it may be the case that adolescents' close identification with extracurricular groups or high levels of peer acceptance within these groups are necessary in order for them to benefit with social self-concept enhancements. 
Accordingly, individual differences in the degree to which youth socially benefited from their varied exposures may have obscured any effects from breadth on social self-concept.

It is also worth noting that self-concept at the high school transition did not affect change in breadth for any self-concept domain. This suggests that early positive views of the self do not facilitate changing breadth. Further, although our models allowed for breadth and self-concept correlations between intercepts and between slopes, only early levels of academic self-concept and breadth were (positively) linked. Youth who had confidence in their academic abilities also tended to take part in a wider assortment of extracurricular contexts in their first year of high school, albeit the strength of this association was only moderate. Yet that early breadth was linked with neither early general self-worth nor early social self-concept suggests that youth who explore a variety of settings at the transition to high school are not necessarily those with particularly positive self-views overall, nor those with affirmative views of their social abilities. Rather, it appears (from positively correlated intercepts between intensity and general self-worth and between intensity and social selfconcept) that those with early positive overall self-views and with positive social identities tend to dedicate greater time towards extracurricular endeavours early-on.

Notably, breadth of participation was a significant unique predictor of academic and general self-concept trajectories; intensity of participation did not predict changes in selfconcept. The premise here is that breadth of activity participation facilitates more exact 'fit' with adolescent strengths, a fit that is not accounted for by intensity of the involvement. Clearly intensity of participation is also part of this formula. Illustratively, early breadth and intensity were strongly correlated in our models. Thus, we have modelled simultaneous change in intensity, because without adequate exposure to experiences, impact on selfconcept would arguably be negligible (Busseri \& Rose-Krasnor, 2010).

\section{Implications}


Although our empirical data do not drill-down to mechanisms of effect, we can speculate as to how wide breadth at the transition to high school might facilitate self-concept development. Such exposure to a variety of experiences may help youth to crystalize their identity, values, and future goals (Williamson et al., 2015). These settings may provide diverse opportunities that are relevant to developmental needs and thus assist adolescents to align their views of self with a positive agenda for the future. That is, adolescents learn more about themselves and what they are capable of through exposure to several different settings, rather than through intensive time spent in one setting. Some settings likely bring certain qualities and attributes to the fore-front more than others (Blomfield \& Barber, 2009; 2011). In some arenas, participation will bring persistence through practice; others, creativity through encouragement of non-linear thinking and positive risk-taking; others, compatibility with peers through reinforcement of positive social skills (Modecki et al., 2014). That said, effect sizes for breadth in relation to self-concept were small-to-moderate across the board. Clearly, other features of adolescents' experiences will also contribute to their self-concept development, including relationships with peers, families, and adults, and experiences within schools and in non-structured settings. Likewise, individual differences, in that some youth are better suited to certain contexts than others and breadth may not operate the same way for all youth, may help to explain the relatively small effects found here.

Yet, study findings still have practical significance and suggest that encouraging a wider breadth of activity participation as youth progress to high school may be a promising strategy for buffering against challenges associated with the high school years. Here we make the case that "a variety of settings is better" for adolescents' exploration of positive identities and roles. But we also add the caveat that some activity settings may be better than others for promoting positive attributes and preventing risk (Hansen, Skorupski, \& Arrington, 2010). 
Making a range of pro-social extracurricular activities available, beyond just sports, is one way that communities might assist youth in their progression to secondary school. Previous findings suggest that particularly within sport settings, risky peers can promote negative roles and dangerous norms, and so contexts in which risk-taking youth gather together, even if structured and supervised, can have iatrogenic effects (Drane et al.; 2017). Thus, given that sport participation in particular, has been linked to hazards such as increased alcohol use, and given that youth settings can sometimes foster negative peer interactions, some degree of caution is also warranted in selecting contexts for exploration.

\section{Limitations}

Although this study offers a number of strengths, several limitations should be considered. Though the sample was large, it consisted primarily of Caucasian youth. Thus, findings cannot be generalized to adolescents from other ethnicities (Dawes et al., 2015). Our sample also transitioned to high school in eighth grade. It is not clear how alternate timing of transitions to high school (i.e.; ninth grade), nor the different extracurricular offerings available elsewhere might lead to alternative conclusions. Further, the requirement for active parental consent may have affected results, because it can lead to under-representation of youth from disadvantaged backgrounds. That said, disadvantaged youth may benefit most from extracurricular participation (Blomfield \& Barber, 2011) and so our effects may be under-stated. Given that school SES rank and breadth had moderate positive associations at each wave, lower SES youth may engage in a narrower breadth of participation during high school. Likewise, multi-group models (in Supplementary Section) indicate that, relative to higher SES youth, lower SES youth engage in a narrower breadth of activities in eighth grade, and show steeper declines in breadth later in high school. Although multi-group multivariate models (also in Supplementary Section) did not show significant differences in associations with self-concept by SES, given that lower SES youth have reduced breadth 
exposure, and given buffering effects of early breadth shown here, enhanced offerings of structured activities within lower SES communities remains a worthwhile objective. Assuming effects are generalizable, enhanced offerings across SES regions may arguably be one tool to assist in addressing social inequality gaps (Marsh \& Kleitman, 2002).

Moreover, several design considerations may have affected results. First, our breadth measure was a fairly blunt instrument, operationalized in terms of variety of participation; we did not conduct more nuanced assessments of particular combinations of activities. Because certain combinations of activities may be especially auspicious for adolescents' long term outcomes, future research could explore different combinations of settings (Strachan, Côté, \& Deakin, 2009), including varying competitiveness of activities which might foster negative peer interactions, as well as how involvement in activities that lack formal structure might contribute to developmental trajectories. Second, although our operationalization is consistent with previous work (Viau, Denault, \& Poulin, 2015), intensity could be conceptualized differently (e.g., hours spent in a primary activity). Assessing intensity in this manner could address ideas about how focusing greater intensity within a specific setting might generate positive outcomes. This could be especially germane during the end of high school when greater intensity is expected, and could lead to stronger intensity effects than uncovered here. Third, exploring more complex interactions between breadth and intensity may be a useful future research direction (Hansen et al., 2010). Fourth, we explored only three aspects of selfconcept, and other self-concept dimensions (e.g. emotional) may be influenced by breadth. Fifth, we did not account for other potentially important characteristics including schools, peers, and adult leaders, which may help to explain positive effects of breadth found here.

Finally, selection effects may be operating to some extent. That early breadth was positively associated with early academic self-concept is one indicator of this possibility. 
However, we did control for socioeconomic status, for early depressed mood and self-esteem, for intensity of participation, and for reciprocal effects of self-concept to good effect.

\section{Conclusion}

Past findings make clear that constructive identity development is linked to a number of positive outcomes, including diminished psychopathology and better educational attainment and achievement (Marsh \& O'Mara, 2008). Youth make choices during adolescence that can affect their life course, winnowing their social and academic opportunities and deciding their future goals and aspirations (Modecki, Zimmer-Gembeck, \& Guerra, 2017). These choices and their associated long-term outcomes are galvanized by their self-concepts. Here, our findings indicate that early exposure to a variety of extracurricular settings is one promising avenue for setting youth onto more auspicious trajectories of general and academic self-concept. We found that self-concept follows a quadratic trajectory of early decline, followed by slight levelling-off, across five years of high school. However, for youth who engage in a wider breadth of extracurricular activities at the high school transition, this decline is reduced. Exposure to diverse structured environments appears to help buffer against early declines in views of the self, generally and in the academic arena. 


\section{References}

Australian Curriculum, Assessment and Reporting Authority (ACARA). (2010). My School Technical Paper. Sydney: ACARA. Retrieved January 11, 2010, from http://www.myschool.edu.au/Resources/pdf/My\%20School\%20ICSEA\%20TECHNI CAL\%20PAPER\%2020091020.pdf.

Blakely-McClure, S. J., \& Ostrov, J. M. (2016). Relational aggression, victimization and selfconcept: Testing pathways from middle childhood to adolescence. Journal of Youth and Adolescence, 45, 376-390.

Blomfield, C. J. \& Barber, B. L. (2011). Developmental experiences during extracurricular activities and Australian adolescents' self-concept: Particularly important for youth from disadvantaged schools. Journal of Youth \& Adolescence, 40, 582-594.

Blomfield, C. J. \& Barber, B. L. (2009). Performing on the stage, the field, or both? Extracurricular activity participation and Australian adolescent self-concept. Journal of Adolescence, 32, 733-739. doi: 10.1016/j.adolescence.2009.01.003

Bohnert, A., Fredricks, J., \& Randall, E. (2010). Capturing unique dimensions of youth organized activity involvement: Theoretical and methodological considerations. Review of Educational Research, 80, 576-610.

Bohnert, A. M., Martin, N. C., \& Garber, J. (2007). Predicting adolescents' organized activity involvement: The role of maternal depression history, family relationship quality, and adolescent cognitions. Journal of Research on Adolescence, 17(1), 221-244.

Bracken, B. A., \& Lamprecht, M. S. (2003). Positive self-concept: An equal opportunity construct. School Psychology Quarterly, 18, 103.

Busseri, M. A., \& Rose-Krasnor, L. (2009). Breadth and intensity: Salient, separable, and developmentally significant dimensions of structured youth activity involvement. British Journal of Developmental Psychology, 27, 907-933. 
Busseri, M. A., \& Rose-Krasnor, L. (2010). Addressing three common issues in research on youth activities: An integrative approach for operationalizing and analyzing involvement. Journal of Research on Adolescence, 20, 583-615.

Busseri, M. A., Rose-Krasnor, L., Willoughby, T., \& Chalmers, H. (2006). A longitudinal examination of breadth and intensity of youth activity involvement and successful development. Developmental Psychology, 42, 1313-1326.

Catalano, R. F., Hawkins, J. D., Berglund, M. L., Pollard, J. A., \& Arthur, M. W. (2002). Prevention science and positive youth development: competitive or cooperative frameworks? Journal of Adolescent Health, 31(6), 230-239.

Chen, H., Cohen, P., \& Chen, S. (2010). How big is a big odds ratio? Interpreting the magnitudes of odds ratios in epidemiological studies. Communications in StatisticsSimulation and Computation ${ }^{\circledR}, 39(4), 860-864$.

Cole, D. A., Martin, J. M., \& Powers, B. (1997). A competency-based model of child depression: A longitudinal study of peer, parent, teacher, and self-evaluations. Journal of Child Psychology and Psychiatry, 38(5), 505-514.

Cole, D. A., Maxwell, S. E., Martin, J. M., Peeke, L. G., Seroczynski, A. D., ...\& Maschman, T. (2001). The development of multiple domains of child and adolescent self-concept: A cohort sequential longitudinal design. Child Development, 72, 1723-1746.

Curran, P. J., Bauer, D. J., \& Willoughby, M. T. (2004). Testing main effects and interactions in latent curve analysis. Psychological Methods, 9(2), 220.

Dawes, N. P., Modecki, K. L., Gonzales, N., Dumka, L., \& Millsap, R. (2015). Mexicanorigin youth participation in extracurricular activities: Predicting trajectories of involvement from 7th to 12th grade. Journal of Youth and Adolescence, 1-17.

Denault, A., \& Poulin, F. (2009). Intensity and breadth of participation in organized activities during the adolescent years: Multiple associations with youth outcomes. Journal of 
Youth \& Adolescence, 38, 1199-1213. doi: 10.1007/s10964-009-9437-5

Drane, C. F., Modecki, K. L., \& Barber, B. L. (2017). Disentangling development of sensation seeking, risky peer affiliation, and binge drinking in adolescent sport. Addictive Behaviors, 66, 60-65.

Eccles, J. S., \& Barber, B. L. (1999). Student council, volunteering, basketball, or marching band: What kind of extracurricular involvement matters? Journal of Adolescent Research, 14(1), 10-43. doi: 10.1177/0743558499141003

Eccles, J. S., Barber, B. L., Stone, M., \& Hunt, J. (2003). Extracurricular activities and adolescent development. Journal of Social Issues, 59(4), 865-890.

Eccles, J. S., \& Gootman, J. A. (2002). Features of positive developmental settings. In J. S. Eccles \& J. A. Gootman (Eds.), Community programs to promote youth development (pp. 86 -118). Washington, DC: National Academies Press

Eccles, J. S., Midgley, C., Wigfield, A., Miller Buchanan, C., Reuman, D., Flanagan, C., \& Mac Iver, D. (1993). Development during adolescence. The impact of stageenvironment fit on young adolescents' experiences in schools and in families. American Psychologist, 48, 90-101. doi: 10.1037//0003-066X.48.2.90

Eccles, J. S., Wigfield, A., Harold, R., \& Blumenfeld, P. B. (1993). Age and gender differences in children's self- and task perceptions during elementary school. Child Development, 64, 830-847. doi: 10.2307/1131221

Enders, C. K. (2010). Applied Missing Data Analysis. New York: The Guildford Press.

Farb, A. F., \& Matjasko, J. L, (2012). Recent advances in research on school-based extracurricular activities and adolescent development. Developmental Review, 1-48.

Farmer, T. W., Estell, D. B., Bishop, J. L., O'neal, K. K., \& Cairns, B. D. (2003). Rejected bullies or popular leaders? The social relations of aggressive subtypes of rural African 
American early adolescents. Developmental Psychology, 39(6), 992.

Feldman, A. M., \& Matjasko, J. L. (2007). Profiles and portfolios of adolescent school-based extracurricular activity participation. Journal of Adolescence, 30, 313-322. doi: 10.1016/j.adolescence.2006.03.004

Fredricks, (2012). Extracurricular participation and academic outcomes: Testing the overscheduling hypothesis. Journal of Youth \& Adolescence, 41, 295-306.

Fredricks, J. A., \& Eccles, J. S. (2002). Children's competence and value beliefs from childhood through adolescence: Growth trajectories in two male-sex-typed domains. Developmental Psychology, 38, 519-533. doi: 10.1037//0012-1649.38.4.519

Gestsdóttir, S., \& Lerner, R. M. (2007). Intentional self-regulation and positive youth development in early adolescence: findings from the 4-h study of positive youth development. Developmental Psychology, 43, 508.

Graham, J. W., Olchowski, A. E., \& Gilreath, T. D. (2007). How many imputations are really needed? Some practical clarifications of multiple imputation theory. Prevention Science, 8, 206-213.

Hansen, D. M., Larson, R. W., \& Dworkin, J. B. (2003). What adolescents learn in organized youth activities: A survey of self-reported developmental experiences. Journal of Research on Adolescence, 13(1), 25-55. doi: 10.1111/1532-7795.1301006

Hansen, D. M., Skorupski, W. P., \& Arrington, T. L. (2010). Differences in developmental experiences for commonly used categories of organized youth activities. Journal of Applied Developmental Psychology, 31(6), 413-421.

Harden, K. P., Turkheimer, E., Emery, R. E., D'Onofrio, B. M., Slutske, W. S., Heath, A. C., \& Martin, N. G. (2007). Marital conflict and conduct problems in children of twins. Child Development, 78(1), 1-18. 
Harter, S. (1999). The Construction of the Self. A Developmental Perspective. New York: The Guilford Press.

Hu \& Bentler (1999). Cutoff criteria for fit indexes in covariance structure analysis: Conventional criteria versus new alternatives, Structural Equation Modeling, 6, 1-55. Jacobs, J. E., Lanza, S., Osgood, D. W., Eccles, J. S., \& Wigfield, A. (2002). Changes in children's self-competence and values: Gender and domain differences across grades one through twelve. Child Development, 73, 509-527. doi: 10.1111/1467-8624.00421

Kline, R. B. (2015). Principles and practice of structural equation modeling. Guilford..

Larson, R. W., Hansen, D. M., \& Moneta, G. (2006). Differing profiles of development experiences across types of organized youth activities. Developmental Psychology, 2, 849-863. doi: 10.1037/0012-1649.42.5.849

Mahoney, J. L., Larson, R. W., Eccles, J. S., \& Lord, H. (2005). Organized activities as developmental contexts for children and adolescents. Organized activities as contexts of development: Extracurricular activities, after-school \& community programs, 3-22.

Marsh, H. W. (1990). A multidimensional, hierarchical model of self-concept: Theoretical and empirical justification. Educational Psychology Review, 2, 77-172.

Marsh, H. W. (1992a). Extracurricular activities: Beneficial extension of the traditional curriculum or subversion of academic goals? Journal of Educational Psychology, 84(4), 553-562. doi: 10.1037//0022-0663.84.4.553

Marsh, H. W. (1992b). Self-Description Questionnaire (SDQ) I: A theoretical andempirical basis for the measurement of multiple dimensions of preadolescent self-concept. An interim test manual and research monograph. Macarthur, New South Wales, Australia: University of Western Sydney, Faculty of Education.

Marsh, H. W. (1992c). Self-Description Questionnaire (SDQ) II: A theoretical and empirical basis for the measurement of multiple dimensions of adolescent self-concept. A test 
manual and research monograph. Macarthur, New South Wales, Australia: University of Western Sydney, Faculty of Education.

Marsh, H. W. (1992d). Self-Description Questionnaire (SDQ) III: A theoretical and empirical basis for the measurement of multiple dimensions of late adolescent selfconcept. An interim test manual and research monograph. Macarthur, New South Wales, Australia: University of Western Sydney, Faculty of Education.

Marsh, H. W. (1989). Age and sex effects in multiple dimensions of self-concept: Preadolescence to early adulthood. Journal of Educational Psychology, 81, 417.

Marsh, H., \& Kleitman, S. (2002). Extracurricular school activities: The good, the bad, and the nonlinear. Harvard Educational Review, 72, 464-515.

Marsh, H. W., \& O'Mara, A. (2008). Reciprocal effects between academic self-concept, selfesteem, achievement, and attainment over seven adolescent years: Unidimensional and multidimensional perspectives of self-concept. Personality and Social Psychology Bulletin, 34(4), 542-552.

Marsh, H. W., \& Yeung, A. S. (1998). Longitudinal structural equation models of academic self-concept and achievement: Gender differences in the development of math and English constructs. American Educational Research Journal, 35(4), 705-738.

McCabe, K. O., Modecki, K. L., \& Barber, B. L. (2016). Participation in organized activities protects against adolescents' risky substance use, even beyond development in conscientiousness. Journal of Youth and Adolescence, 45, 2292-2306..

Miller, R. B., \& Wright, D. W. (1995). Detecting and correcting attrition bias in longitudinal family research. Journal of Marriage and the Family, 921-929.

Modecki, K.L (2016). Do risks matter? Variable and person-centered approaches to adolescents' problem behavior. Journal of Applied Developmental Psychology, 42, 820. 
Modecki, K.L., Barber, B.L., Eccles, J.E. (2014). Binge drinking trajectories across adolescence: Extra-curricular activities are protective for youth with early pubertal development. Journal of Adolescent Health, 54 (1), 61-66

Modecki, K. L., Barber, B. L., \& Vernon, L. (2013). Mapping developmental precursors of cyber-aggression: Trajectories of risk predict perpetration and victimization. Journal of Youth and Adolescence, 42(5), 651-661.

Modecki, K.L. Zimmer-Gemback, M \& Guerra, N. (2017). Emotion regulation, coping and decision-making: Three linked skills for preventing externalizing problems in adolescence. Child Development, 88(2).

Molloy, L. E., Ram, N., \& Gest, S. D. (2011). The storm and stress (or calm) of early adolescent self-concepts: Within- and between-subjects variability. Developmental Psychology, 47, 1589-1607. doi: 10.1037/a0025413

Muijs, R. D. (1997). Predictors of academic achievement and academic self-concept: a longitudinal perspective. British Journal of Educational Psychology, 67, 263-277.

Musu-Gillette, L. E., Wigfield, A., Harring, J. R., \& Eccles, J. S. (2015). Trajectories of change in students' self-concepts of ability and values in math and college major choice. Educational Research and Evaluation, 21(4), 343-370.

Muthén, L. K. \& Muthén, B. FIML vs. MI (2011) [online comment]. Retrieved from http://www.statmodel.com/discussion/messages/22/2440.html?1425099486

Muthén, L. K. \& Muthén, B. O. (1998-2012). Mplus User's Guide. Seventh Edition. Los Angeles, CA: Muthén \& Muthén.

Nagy, G., Watt, H. M. G., Eccles, J. S., Trautwein, U., Ludtke, O., \& Baumert, J. (2010). The development of students' mathematics self-concept in relation to gender: Different 
countries, different trajectories? Journal of Research on Adolescence, 20, 482-506. doi: $10.111 / \mathrm{j} .1532-7795.2010 .00644 . \mathrm{x}$

O'Mara, A. J., Marsh, H. W., Craven, R. G., \& Debus, R. L. (2006). Do self-concept interventions make a difference? A synergistic blend of construct validation and metaanalysis. Educational Psychologist, 4, 181-206.

Park, J. (2003). Adolescent self-concept and health into adulthood. Health Reports, 14(Supp).

Simpkins, S. D., Eccles, J. S., \& Becnel, J. N. (2008). The mediational role of adolescents' friends in relations between activity breadth and adjustment. Developmental Psychology, 44(4), 1081.

Skaalvik, E. M., \& Hagtvet, K. A. (1990). Academic achievement and self-concept: An analysis of causal predominance in a developmental perspective. Journal of Personality and Social Psychology, 58(2), 292.

Strachan, L., Côté, J., \& Deakin, J. (2009). "Specializers" versus "samplers" in youth sport: comparing experiences and outcomes. The Sport Psychologist, 23, 77-92.

Vernon, L., Modecki, K. L., \& Barber, B. L. (2018). Mobile Phones in the Bedroom: Trajectories of Sleep Habits and Subsequent Adolescent Psychosocial Development. Child Development, 89, 66-77.

Wigfield, A., Eccles, J. S., Mac Iver, D., Reuman, D. A., \& Midgley, C. (1991). Transitions during early adolescence: Changes in children's domain-specific self-perceptions and general self-esteem across the transition to junior high school. Developmental Psychology, 27, 552.

Williamson, A. A., Modecki, K. L., \& Guerra, N. G. (2015). SEL programs in high school. Handbook of Social and Emotional Learning: Research and Practice, 181-196. 
Breadth of Activity Mitigate Self-Concept Declines 41

Yuan, K., \& Bentler, P. M. (2000). Three likelihood-based methods for mean and covariance structure analysis with nonnormal missing data. Sociological Methodology, 30, 165200. doi: 10.1111/0081-1750.00078 
Table 1. Means, standard deviations, and correlations among study variables.

\begin{tabular}{|c|c|c|c|c|c|c|c|c|c|c|c|c|c|c|c|c|c|c|c|c|c|c|c|c|c|}
\hline Variables & 1 & 2 & 3 & 4 & 5 & 6 & 7 & 8 & 9 & 10 & 11 & 12 & 13 & 14 & 15 & 16 & 17 & 18 & 19 & 20 & 21 & 22 & 23 & 24 & 25 \\
\hline 1. G8-general & - & & & & & & & & & & & & & & & & & & & & & & & & \\
\hline 2. G9-general & $.52 * *$ & - & & & & & & & & & & & & & & & & & & & & & & & \\
\hline 3. G10 general & $.50 * *$ & $.58^{* *}$ & - & & & & & & & & & & & & & & & & & & & & & & \\
\hline 4. G11-general & $.39 * *$ & $.56^{* *}$ & $.60^{* *}$ & - & & & & & & & & & & & & & & & & & & & & & \\
\hline 5. G12-general & $.34 * *$ & $.45^{* *}$ & $.53^{* *}$ & $.66^{* *}$ & - & & & & & & & & & & & & & & & & & & & & \\
\hline 6. G8-social & $.61 * *$ & $.30 * *$ & $.29 * *$ & $.24 * *$ & $.24 * *$ & - & & & & & & & & & & & & & & & & & & & \\
\hline 7. G9-social & $.35 * *$ & $.61 * *$ & $.34 * *$ & $.35^{* *}$ & $.28^{* *}$ & $.49 * *$ & - & & & & & & & & & & & & & & & & & & \\
\hline 8. G10-social & $.38 * *$ & $.38 * *$ & $.61^{* *}$ & $.40^{* * *}$ & $.32 * *$ & $.49 * *$ & $.54 * *$ & - & & & & & & & & & & & & & & & & & \\
\hline 9. G11-social & $.28 * *$ & $.39^{* *}$ & $.40^{* *}$ & $.63^{* *}$ & $.38^{* *}$ & $.41^{* *}$ & $.49^{* *}$ & $.60^{* *}$ & - & & & & & & & & & & & & & & & & \\
\hline 10.G12-social & $.23 * *$ & $.29 * *$ & $.33^{* *}$ & $.43^{* *}$ & $.54 * *$ & $.40 * *$ & $.46^{* *}$ & $.52 * *$ & $.64 * *$ & - & & & & & & & & & & & & & & & \\
\hline 11. G8-academic & $.75 * *$ & $.43 * *$ & $.44^{* *}$ & $.38^{* *}$ & $.35^{* *}$ & $.51^{* *}$ & $.26^{* *}$ & $.31 * *$ & $.24 * *$ & $.20 * *$ & - & & & & & & & & & & & & & & \\
\hline 12. G9-academic & $.45^{* *}$ & $.75^{* * *}$ & $.49^{* *}$ & $.44^{* *}$ & $.37 * *$ & $.22 * *$ & $.45^{* *}$ & $.28 * *$ & $.28 * *$ & $.18 * *$ & $.53^{* *}$ & - & & & & & & & & & & & & & \\
\hline 13. G10-academic & $.40 * *$ & $.47^{* *}$ & $.78^{* *}$ & $.49^{* *}$ & $.44 * *$ & $.20 * *$ & $.21^{* *}$ & $.43^{* *}$ & $.28^{* *}$ & $.23^{* *}$ & $.49 * *$ & $.57 * *$ & - & & & & & & & & & & & & \\
\hline 14 G11-academic & $.32 * *$ & $.46^{* *}$ & $.47^{* *}$ & $.74 * *$ & $.52 * *$ & $.15^{* * *}$ & $.23^{* *}$ & $.23 * *$ & $.43 * *$ & $.29 * *$ & $.41 * *$ & $.54 * *$ & $.59 * *$ & - & & & & & & & & & & & \\
\hline 15. G12-academic & $.30 * *$ & $.39 * *$ & $.43^{* *}$ & $.48^{* *}$ & $.72 * *$ & $.15^{* *}$ & $.17^{* *}$ & $.19^{* *}$ & $.24 * *$ & $.34 * *$ & $.41 * *$ & $.47^{* *}$ & $.55 * *$ & $.60^{* *}$ & - & & & & & & & & & & \\
\hline 16. G8-breadth & $.15^{* *}$ & $.19 * *$ & $.17^{* *}$ & $.21^{* *}$ & $.12 * *$ & $.09^{* *}$ & $.10^{* *}$ & $.11^{* *}$ & $.15^{* *}$ & $.10^{* *}$ & $.17^{* *}$ & $.17 * *$ & $.18 * *$ & $.20^{* * *}$ & $.11 * *$ & - & & & & & & & & & \\
\hline 17. G9-breadth & $.15^{* *}$ & $.19 * *$ & $.19 * *$ & $.20^{* *}$ & $.12 * *$ & $.07 *$ & $.12^{* * *}$ & $.14^{* *}$ & $.15^{* *}$ & $.09^{* *}$ & $.15^{* *}$ & $.23 * *$ & $.20 * *$ & $.18^{* * *}$ & $.13 * *$ & $.51 * *$ & - & & & & & & & & \\
\hline 18. G10-breadth & $.18^{* *}$ & $.21^{* *}$ & $.23^{* *}$ & $.21^{* *}$ & $.12 * *$ & $.09 * *$ & $.12 * *$ & $.13^{* *}$ & $.18^{* *}$ & $.09 * *$ & $.18^{* *}$ & $.21^{* *}$ & $.23 * *$ & $.22 * *$ & $.14^{* *}$ & $.48^{* *}$ & $.56^{* *}$ & - & & & & & & & \\
\hline 19. G11-breadth & $.15^{* *}$ & $.21 * *$ & $.20^{* *}$ & $.24 * *$ & $.18 * *$ & $.11^{* *}$ & $.15^{* *}$ & $.15^{* *}$ & $.22 * *$ & $.16^{* *}$ & $.12 * *$ & $.21 * *$ & $.22 * *$ & $.26^{* *}$ & $.15^{* *}$ & $.44 * *$ & $.51 * *$ & $.58 * *$ & - & & & & & & \\
\hline 20. G12-breadth & $.10^{* *}$ & $.17^{* *}$ & $.14^{* *}$ & $.18^{* *}$ & $.17^{* *}$ & .04 & $.07 *$ & $.07 *$ & $.13^{* *}$ & $.08 *$ & $.11 * *$ & $.13^{* *}$ & $.17 * *$ & $.17 * *$ & $.13^{* * *}$ & $.25 * *$ & $.31 * *$ & $.41 * *$ & $.54 * *$ & - & & & & & \\
\hline 21. G8-intensity & $.19^{* *}$ & $.19^{* *}$ & $.16^{* *}$ & $.22 * *$ & $.13^{* *}$ & $.15^{* *}$ & $.16^{* *}$ & $.14^{* *}$ & $.19 * *$ & $.16^{* * *}$ & $.15^{* *}$ & $.11 * *$ & $.15 * *$ & $.16^{* * *}$ & $.09 * *$ & $.57 * *$ & $.35 * *$ & $.31 * *$ & $.33 * *$ & $.27 *$ & - & & & & \\
\hline 22. G9-intensity & $.16^{* *}$ & $.22 * *$ & $.18^{* *}$ & $.22 * *$ & $.14^{* *}$ & $.15^{* *}$ & $.21 * *$ & $.17^{* *}$ & $.21 * *$ & $.15^{* * *}$ & $.11 * *$ & $.16^{* *}$ & $.14 * *$ & $.14 * *$ & $.10^{* *}$ & $.32 * *$ & $.50 * *$ & $.36 * *$ & $.36^{* *}$ & $.29 *$ & $.57^{* *}$ & - & & & \\
\hline 23. G10-intensity & $.16^{* *}$ & $.19^{* *}$ & $.16^{* *}$ & $.25 * *$ & $.19^{* *}$ & $.13^{* *}$ & $.18^{* *}$ & $.14 * *$ & $.25 * *$ & $.21 * *$ & $.09 * *$ & $.10 * *$ & $.14 * *$ & $.17 * *$ & $.09 * *$ & $.24 * *$ & $.28 * *$ & $.34 * *$ & $.54 * *$ & $.42 *$ & $.52 * *$ & $.63 * *$ & - & & \\
\hline 24. G11-intensity & $.16^{* *}$ & $.19^{* *}$ & $.16^{* *}$ & $.25 * *$ & $.19^{* *}$ & $.13^{* *}$ & $.18^{* *}$ & $.14 * *$ & $.25 * *$ & $.21 * *$ & $.09^{* *}$ & $.10 * *$ & $.14 * *$ & $.17 * *$ & $.09 * *$ & $.24 * *$ & $.28 * *$ & $.34 * *$ & $.54 * *$ & $.42 *$ & $.48 * *$ & $.49^{* *}$ & $.61^{* *}$ & - & \\
\hline 25. G12-intensity & $.10^{* *}$ & $.13^{* *}$ & $.11 * *$ & $.19 * *$ & $.15^{* *}$ & $.10 * *$ & $.11 * *$ & $.08 *$ & $.18^{* *}$ & $.13 * *$ & $.08 *$ & $.06^{*}$ & $.09 * *$ & $.09 * *$ & .04 & $.19 * *$ & $.18^{* *}$ & $.26 * *$ & $.32 * *$ & $.61 *$ & $.45^{* *}$ & $.41^{* *}$ & $.52^{* *}$ & $.59^{* *}$ & - \\
\hline Mean & 4.58 & 4.45 & 4.38 & 4.33 & 4.38 & 4.66 & 4.60 & 4.49 & 4.43 & 4.80 & 4.64 & 4.47 & 4.42 & 4.39 & 4.46 & 1.56 & 1.53 & 1.45 & 1.24 & 1.15 & 9.13 & 9.05 & 10.71 & 9.98 & 7.77 \\
\hline Std. Deviation & 0.93 & 1.00 & 1.00 & 0.94 & 0.88 & 0.98 & 1.00 & 0.99 & 1.01 & 0.92 & 1.01 & 1.12 & 1.07 & 1.00 & .92 & .97 & .92 & .93 & .89 & .95 & 7.10 & 8.51 & 8.34 & 8.08 & 7.79 \\
\hline
\end{tabular}

Note: G8 $=$ Grade 8, G9 = Grade 9, G10 = Grade 10, G11 = Grade 11, G12 = Grade 12.

General, social, academic self-concept indicators.

${ }^{*} p<.05, * * p \leq .001$ 
Table 2. Univariate models and effects of covariates on general self-worth, social self-concept, and academic self-concept.

\begin{tabular}{|c|c|c|c|c|c|c|}
\hline & \multicolumn{2}{|c|}{ General Self-Worth } & \multicolumn{2}{|c|}{ Social Self-Concept } & \multicolumn{2}{|c|}{ Academic Self-Concept } \\
\hline & Model 1 & Model 2 & Model 1 & Model 2 & Model 1 & Model 2 \\
\hline \multicolumn{7}{|l|}{ Fixed effects } \\
\hline Intercept (Grade 8 mean) & $4.59(.03) 6.56 * * *$ & $4.63(.03) 6.10 * * *$ & $4.67(.03) 6.33 * * *$ & $4.76(.07) 5.92 * * *$ & $4.66(.03) 5.64 * * *$ & $4.69(.04) 5.55 * * *$ \\
\hline Gender & & $-.11(.05)-.07 *$ & & $-.23(.05)-.14 * * *$ & & $-.11(.06)-.07+$ \\
\hline Ethnicity & & $.01(.06) .00$ & & $.17(.07) .08 *$ & & $.17(.08) \mathbf{. 0 7}^{+}$ \\
\hline SES & & $.00(.00) .01$ & & $.00(.00) .04$ & & $.01(.00) .11 * *$ \\
\hline Early depressed mood & & $.04(.03) .05+$ & & $-.10(.03)-.12 * * *$ & & $.04(.03) .04$ \\
\hline Early self-esteem & & $.59(.02) .85^{* * *}$ & & $.48(.03) .64 * * *$ & & $.50(.03) .64 * * *$ \\
\hline Linear slope (time) & $-.16(.03)-.45 * * *$ & $-.24(.03)-.55 * * *$ & $-.12(.03)-.32 * * *$ & $-.15(.04)-.31 * * *$ & $-.19(.03)-.41 * * *$ & $-.28(.04)-.58 * * *$ \\
\hline Gender & & $.20(.05) .22 * * *$ & & $.09(.06) .09$ & & $.19(.06) .19 * *$ \\
\hline Ethnicity & & $.10(.07) .08$ & & $-.02(.08)-.02$ & & $.07(.09) .05$ \\
\hline SES & & $.01(.00) .16^{* * *}$ & & $.01(.00) .11$ & & $.01(.00) .07$ \\
\hline Early depressed mood & & $-.12(.03)-.27 * * *$ & & $-.03(.03)-.05$ & & $-.12(.03)-.23 * * *$ \\
\hline Early self-esteem & & $-.20(.03)-.50 * * *$ & & $-.17(.03)-.38 * * *$ & & $-.18(.03)-.39 * * *$ \\
\hline Quadratic slope $\left(\right.$ Time $\left.^{2}\right)$ & $.03(.01) .32 * * *$ & $.04(.01) . \mathbf{4 3} * * *$ & $.02(.01) .20 * *$ & $.02(.01) .16+$ & $.03(.01) .37^{* * *}$ & $.05(.01) .54 * * *$ \\
\hline Gender & & $-.04(.01)-.19 * *$ & & $-.01(.01)-.05$ & & $-.04(.02)-.18 *$ \\
\hline Ethnicity & & $-.03(.02)-.10$ & & $-.01(.02)-.02$ & & $-.02(.02)-.08$ \\
\hline SES & & $-.00(.00)-.08$ & & $.00(.00)-.04$ & & $.00(.00)-.04$ \\
\hline Early depressed mood & & $.03(.01) .27 * * *$ & & $.01(.01) .05$ & & $.02(.01) .24 * *$ \\
\hline Early self-esteem & & $.03(.01) .31 * * *$ & & $.03(.01) .26 * *$ & & $.03(.01) .28^{* *}$ \\
\hline \multicolumn{7}{|l|}{ Random effects } \\
\hline Intercept & $.49(.06) \mathbf{1}^{* * *}$ & $.17(.05) .30 * * *$ & $.54(.07) 1^{* * *}$ & $.32(.06) .50 * * *$ & $.68(.08) \mathbf{1}^{* * *}$ & $.41(.06) .57 * * *$ \\
\hline Linear slope & $.13(.05) 1^{*}$ & $.13(.04) .70 * *$ & $.15(.06) 1 * *$ & $.20(.05) .86 * * *$ & $.21(.06) \mathbf{1}^{* *}$ & $.20(.06) .82 * *$ \\
\hline Quadratic slope & $.01(.00) \mathbf{1}^{* *}$ & $.01(.00) .84 * *$ & $.01(.00) 1 * *$ & $.01(.00) .94 * * *$ & $.01(.00) 1^{* *}$ & $.01(.00) .87 *$ \\
\hline $\mathrm{CFI}$ & 1.00 & .99 & .996 & .99 & 1.00 & .997 \\
\hline RMSEA & .001 & .029 & .026 & .028 & .000 & .017 \\
\hline SRMR & .018 & .024 & .029 & .033 & .017 & .016 \\
\hline
\end{tabular}

Note: Standardized coefficients in bold; significance for unstandardized coefficients. Gender: female =0, male $=1$; Ethnicity: Caucasian $=0$, Other $=1 ;$ SES $=$ low scores indicate lower SES.

$* p<.05, * * p<.01, * * * p<.001,+p<.10$. 
Table 3. Univariate models and effects of covariates on ECA Breadth and ECA Intensity.

\begin{tabular}{|c|c|c|c|c|}
\hline & \multicolumn{2}{|c|}{ ECA Breadth } & \multicolumn{2}{|c|}{ ECA Intensity } \\
\hline & Model 1 & Model 2 & Model 1 & Model 2 \\
\hline \multicolumn{5}{|l|}{ Fixed effects } \\
\hline Intercept (Grade 8 mean) & $1.57(.03) 2.39 * * *$ & $1.68(.04) 2.50 * * *$ & $9.30(.23) \mathbf{1 . 8 0} * * *$ & $8.44(.31) \mathbf{1 . 6 2} * * *$ \\
\hline Gender & & $-.24(.06)-.18 * * *$ & & $1.39(.46) .13 * *$ \\
\hline Ethnicity & & $-.14(.08)-.07^{+}$ & & $-1.82(.66)-.12 * *$ \\
\hline SES & & $.03(.00) . \mathbf{4 1} * * *$ & & $.18(.03) .31 * * *$ \\
\hline Early depressed mood & & $.04(.03) .06$ & & $.02(.25) .00$ \\
\hline Early self-esteem & & $.08(.03) .04 * *$ & & $.85(.232) .18 * * *$ \\
\hline Linear slope (time) & $-.03(.03)-.16$ & $-.02(.04)-.08$ & $1.37(.21) .62 * * *$ & $.99(.31) .35 * *$ \\
\hline Gender & & $-.03(.05)-.07$ & & $.78(.47) .14+$ \\
\hline Ethnicity & & $.11(.07) .18$ & & $.60(.66) .07$ \\
\hline SES & & $-.00(.00)-.05$ & & $.02(.03) .07$ \\
\hline Early depressed mood & & $.01(.03) .04$ & & $-.02(.26)-.01$ \\
\hline Early self-esteem & & $.01(.03)-.01$ & & $.04(.23) .02$ \\
\hline Quadratic slope $\left(\right.$ Time $\left.^{2}\right)$ & $-.02(.01)-.32 * *$ & $-.03(.01)-.41 * *$ & $-.48(.05)-.76^{* * *}$ & $-.37(.08)-.48 * * *$ \\
\hline Gender & & $.02(.01)-.07$ & & $-.23(.12)-.15+$ \\
\hline Ethnicity & & $-.03(.02) .18$ & & $-.12(.17)-.06$ \\
\hline SES & & $.00(.00)-.05$ & & $-.01(.01)-.11$ \\
\hline Early depressed mood & & $-.00(.01)-.01$ & & $-.01(.07)-.06$ \\
\hline Early self-esteem & & $-.00(.01) .04$ & & $-.04(.06)-.02$ \\
\hline \multicolumn{5}{|l|}{ Random effects } \\
\hline Intercept & $.43(.06) 1^{* * *}$ & $.35(.06) .77^{* * *}$ & $26.66(2.64) \mathbf{1}^{* * *}$ & $22.03(2.35) .81 * * *$ \\
\hline Linear slope & $.04(.05) \mathbf{1}$ & $.05(.05) .96$ & $4.87(3.14) \mathbf{1}^{*}$ & $7.77(2.65) .97 * *$ \\
\hline Quadratic slope & $.01(.00) 1$ & $.01(.00) .95$ & $.40(19) 1^{* *}$ & $.57(.17) .95^{* *}$ \\
\hline CFI & .996 & .99 & .96 & .98 \\
\hline RMSEA & .028 & .03 & .056 & .042 \\
\hline SRMR & .022 & .025 & .042 & .023 \\
\hline
\end{tabular}

Note: Standardized coefficients in bold; significance for unstandardized coefficients. Gender: female =0, male $=1$; Ethnicity: Caucasian $=0$, Other $=1$; SES $=$ low scores indicate lower SES.

$* p<.05, * * p<.01, * * * p<.001,+p<.10$. 
Table 4.

Factor regression coefficients and correlation coefficients from general self-worth multivariate process model.

\begin{tabular}{|c|c|c|c|c|c|c|}
\hline \multirow[b]{2}{*}{ Factor } & \multicolumn{3}{|c|}{ ECA Intensity } & \multicolumn{3}{|c|}{ ECA Breadth } \\
\hline & Intercept & Linear Slope & Quadratic Slope & Intercept & Linear Slope & Quadratic Slope \\
\hline \multicolumn{7}{|l|}{ General Self-Worth } \\
\hline Intercept & $.42(.15) .20 * *$ & $1.03(.86) .27$ & $-.32(.22)-.32$ & $.04(.02) .16+$ & $.01(.10) .03$ & $-.00(.03)-.02$ \\
\hline Linear Slope & $-.01(.01)-.13$ & $.11(.21) . \mathbf{1 0}$ & & $.31(.10) .41 * *$ & $.01(.02) .08$ & \\
\hline Quadratic Slope & $.00(.00) .09$ & & $.01(.01) .10$ & $-.07(.02)-.40 *$ & & $.00(.00) .14$ \\
\hline \multicolumn{7}{|l|}{ ECA Intensity } \\
\hline Intercept & & & & $1.63(.31) .61^{* * *}$ & $.00(.01) . \mathbf{0 3}$ & $-.00(.00)-.04$ \\
\hline Linear Slope & & & & $1.42(.85) .31+$ & $.08(.28) .09$ & \\
\hline Quadratic Slope & & & & $-.41(.18)-.34 *$ & & .01.(02).12 \\
\hline
\end{tabular}

Note. Model fit: $\chi^{2}(105)=228.07, p<.001 . \mathrm{RMSEA}=.032, \mathrm{CFI}=.98, \mathrm{SRMR}=.031$.

All models include gender, SES, ethnicity, early depressed mood, and early self-esteem as time-invariant covariates. Standardized coefficients in bold; significance for unstandardized coefficients. Standardized values are correlation coefficients for correlated intercepts, linear, and quadratic slopes.

Values are regression coefficients for slopes regressed on intercepts.

$+p<.10, * p<.05, * * p<.01$ 
Table 5 .

Factor regression coefficients and correlation coefficients from social self-concept multivariate process model.

\begin{tabular}{|c|c|c|c|c|c|c|}
\hline \multirow[b]{2}{*}{ Factor } & \multicolumn{3}{|c|}{ ECA Intensity } & \multicolumn{3}{|c|}{ ECA Breadth } \\
\hline & Intercept & Linear Slope & Quadratic Slope & Intercept & Linear Slope & Quadratic Slope \\
\hline \multicolumn{7}{|l|}{ Social Self-Concept } \\
\hline Intercept & $.41(.18) .16 *$ & $.88(.70) .23$ & $-.26(.18)-.26$ & $-.03(.02)-.11$ & $.01(.08) . \mathbf{0 3}$ & $.01(.08) .08$ \\
\hline Linear Slope & $-.01(.01)-.13$ & $.21(.21) .19$ & & $.20(.11) .30+$ & $.03(.02) .24$ & \\
\hline Quadratic Slope & $.00(.00) .07$ & & .01(.01). 18 & $-.03(.03)-.21$ & & $.00(.00) .23$ \\
\hline \multicolumn{7}{|l|}{ ECA Intensity } \\
\hline Intercept & & & & $1.71(.28) .62 * * *$ & $.00(.01) .02$ & $-.00(.00)-.07$ \\
\hline Linear Slope & & & & $1.45(.78) . \mathbf{3 2}^{+}$ & $.08(.28) .09$ & \\
\hline Quadratic Slope & & & & $-.46(.18)-.39 *$ & & $.01(.02) .09$ \\
\hline
\end{tabular}

Note. Model fit: $, \chi^{2}(105)=238.76, p<.001 . \mathrm{RMSEA}=.03, \mathrm{CFI}=.98, \mathrm{SRMR}=.032$.

All models include gender, SES, ethnicity, early depressed mood, and early self-esteem as time-invariant covariates. Standardized coefficients in bold; significance for unstandardized coefficients. Standardized values are correlation coefficients for correlated intercepts, linear, and quadratic slopes.

Values are regression coefficients for slopes regressed on intercepts.

$* p<.05, * * p<.01$. 
Table 6.

Factor regression coefficients and correlation coefficients from academic self-concept multivariate process model.

\begin{tabular}{|c|c|c|c|c|c|c|}
\hline \multirow[b]{2}{*}{ Factor } & \multicolumn{3}{|c|}{ ECA Intensity } & \multicolumn{3}{|c|}{ ECA Breadth } \\
\hline & Intercept & Linear Slope & Quadratic Slope & Intercept & Linear Slope & Quadratic Slope \\
\hline \multicolumn{7}{|c|}{ Academic Self-Concept } \\
\hline Intercept & $.23(.19) .08$ & $-.06(.68)-.02$ & $-.01(.17)-.01$ & $.08(.03) .25 * *$ & $-.04(.07)-.09$ & $-.00(.02)-.02$ \\
\hline Linear Slope & $-.01(.01)-.13$ & $.27(.23) .25$ & & $.24(.11) .34^{*}$ & $.04(.03) .28$ & \\
\hline Quadratic Slope & $.00(.00) .14$ & & $.01(.01) .19$ & $-.06(.03)-.41 *$ & & $.00(.00) .17$ \\
\hline \multicolumn{7}{|l|}{ ECA Intensity } \\
\hline Intercept & & & & $1.67(.30) .61 * *$ & $.00(.01) .02$ & $-.00(.00)-.04$ \\
\hline Linear Slope & & & & $1.49(.83) .32+$ & $.09(.28) .10$ & \\
\hline Quadratic Slope & & & & $-.44(.18)-.37 *$ & & $.01(.02) .11$ \\
\hline
\end{tabular}

Note. $\chi^{2}(105)=234.09, \mathrm{CFI}=.98, \mathrm{RMSEA}=.03, \mathrm{SRMR}=.03$

All models include gender, SES, ethnicity, early depressed mood, and early self-esteem as time-invariant covariates. Standardized coefficients in bold; significance for unstandardized coefficients. Standardized values are correlation coefficients for correlated intercepts, linear, and quadratic slopes.

Values are regression coefficients for slopes regressed on intercepts.

$* p<.05, * * p<.01$. 
Figure 1A. Change in general self-worth by early breadth of participation, female adolescents.

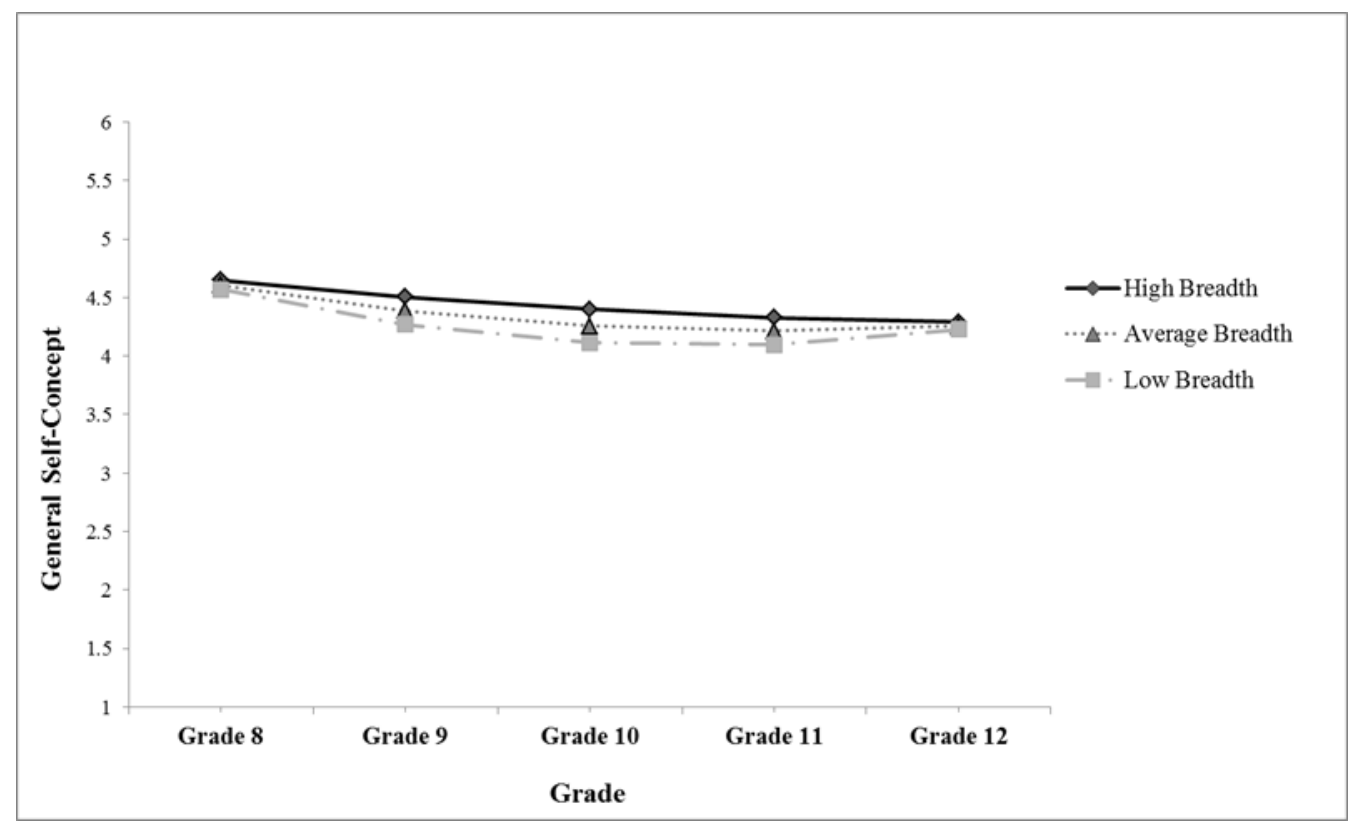

Note. Estimated trajectories at $1 \mathrm{SD}$ above and below mean $8^{\text {th }}$ grade breadth.

Figure 1B. Change in general self-worth by early breadth of participation, male adolescents.

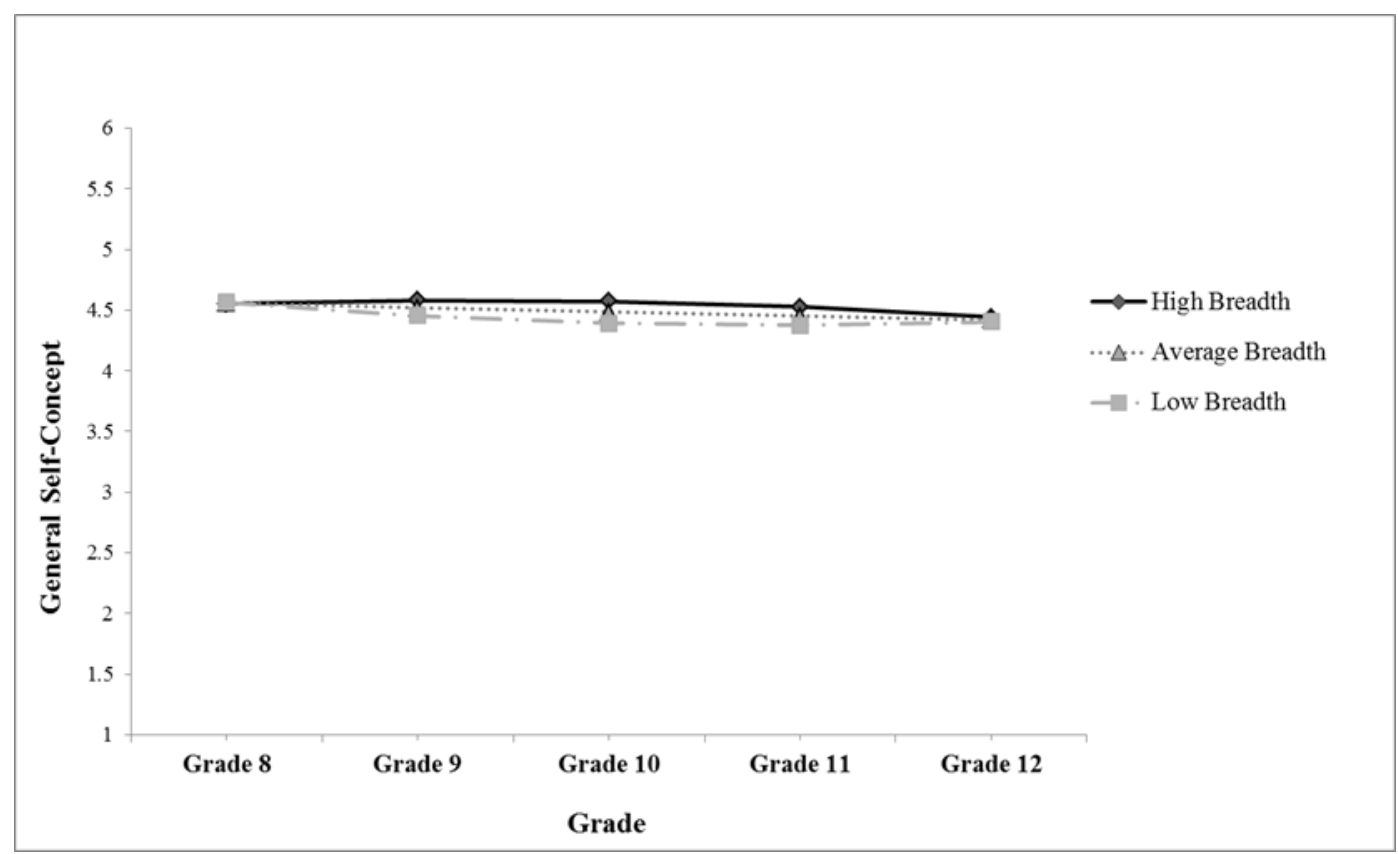

Note. Estimated trajectories at $1 \mathrm{SD}$ above and below mean $8^{\text {th }}$ grade breadth. 
Figure 1C. Change in academic self-concept by early breadth, female adolescents.

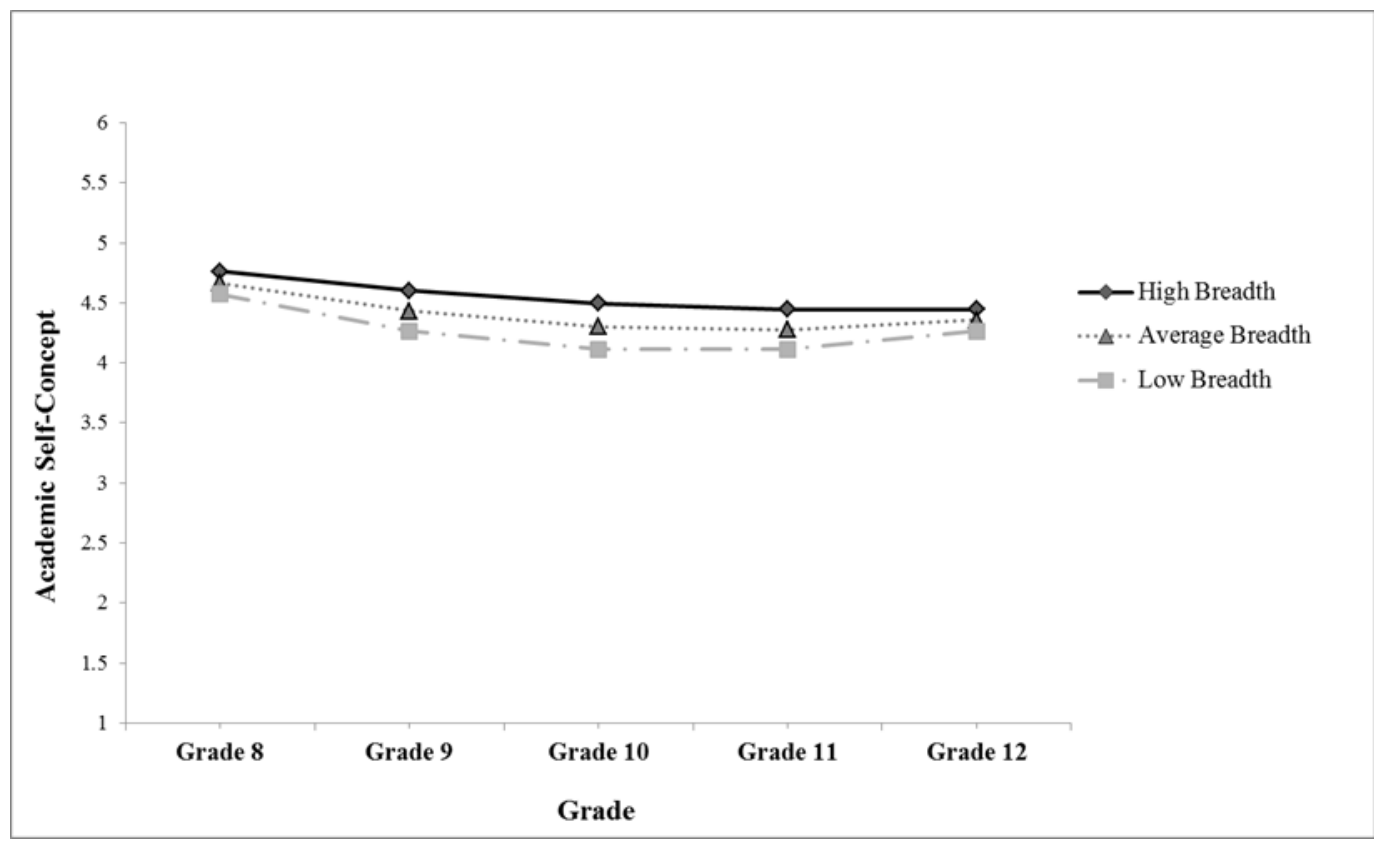

Note. Estimated trajectories at $1 \mathrm{SD}$ above and below mean $8^{\text {th }}$ grade breadth.

Figure 1D. Change in academic self-concept by early breadth, male adolescents.

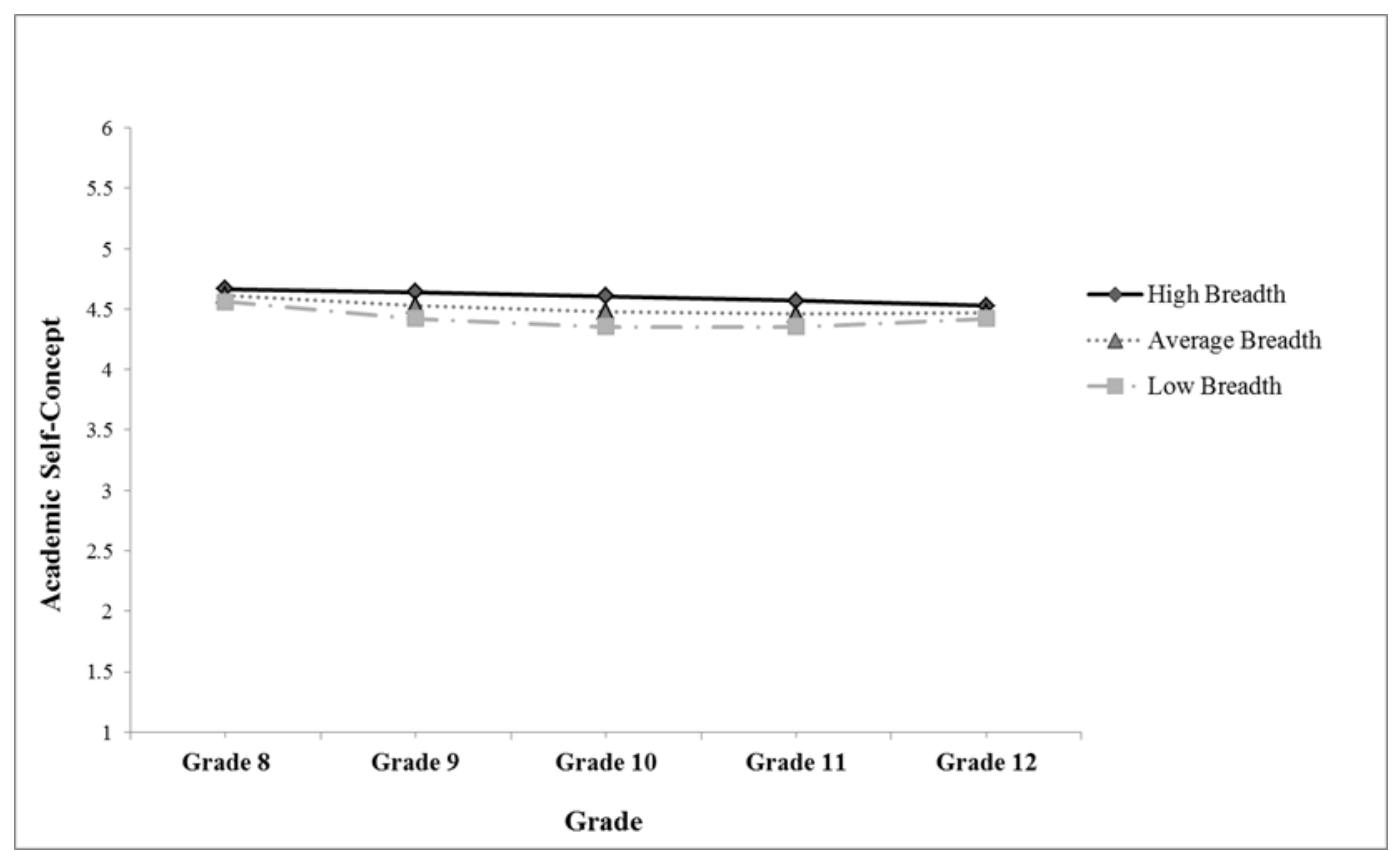

Note. Estimated trajectories at $1 \mathrm{SD}$ above and below mean $8^{\text {th }}$ grade breadth. 


\section{Supplementary Materials}

\section{Time-Invariant Covariates.}

In Grade 8 participants reported their gender (females=0; males $=1$ ) and ethnicity (Caucasian=0; all other ethnicities=1). In addition, self-esteem and depressed mood in Grade 8 were also included as covariates in order to help control for potential selection effects.

Self-esteem was measured based in eighth grade. The measure was based on the mean for three items used in previous research, where the validity of the scale has been ascertained (Vernon, Modecki \& Barber, 2017). Items were measured on a 6-point scale from 1 (never) to 6 (daily) and include, "How often do you feel sure about yourself?" Chronbach's alpha $=.88$.

Depressed mood was measures based on the mean of five items designed to tap emotional wellbeing. An example item is "How often do you feel there is nothing nice you can look forward to?'Validity of the scale has also been supported in previous work (Modecki, Vernon, \& Baber, 2013). Responses ranged from 1 (never) to 6 (daily). Chronbach's alpha $=.75$.

\section{Attrition.}

Tests for attrition bias affecting internal validity included comparing correlation coefficients at wave 1 for the overall sample and longitudinal participants at wave 5, using Fisher's Z statistical test. There were no significant differences, indicating no apparent attrition bias (Miller \& Wright, 1995). Tests for possible bias affecting external validity involved comparing youth who droppedout by the final wave versus remained in the study on an array of constructs. Logit regression analyses predicting later participation vs not indicated some significant predictors; participants across all waves were more likely to be female, have higher SES, report greater ECA activities and breadth, and higher academic self-concept at wave 1 . However the amount of explained variance in the overall equation was quite small, as indicated by pseudo $\mathrm{R}^{2}$ for overall equation $=$ .09 (see Miller \& Wright, 1995). That said, in a further test for possible bias, we elected to run sensitivity tests by including Inverse Probability Weighting (IPW) for missing data (probability of participation within the models; e.g. Harden et al., 2007), in all final analyses and results were substantively the same.

\section{Treatment of Missing Data.}

Two customary procedures implemented for managing missing data common to longitudinal research are Full Information Maximum Likelihood (FIML) and Multiple Imputation (MI). Both of these are based on MAR assumptions, though are considered somewhat robust to violations (Enders, 2010). However, they have slightly different advantages, and as result, we ran sensitivity tests using both to help ensure findings were robust. 
Little's test indicted data were not MCAR. Although there is no definitive test for MAR, we were proactive in satisfying the MAR assumption across our models. First, in our FIML models, we included key variables (wave 1 self esteem and wave 1 depression) that might explain missingness (Enders, 2010). Continuous covariates were also explicitly listed in the models, which in Mplus is a programming possibility that makes the covariates single indicators of a latent construct and, as a result, converts the X's to pseudo Y's, while preserving the exogenous status of the variables in the model (Muthén \& Muthén, 2011). Thus, all parameters were estimated using Maximum Likelihood estimation (Yuan \& Bentler, 2000); the advantage of the FIML procedure being that it uses all the information of the observed data (Enders, 2010).

Second, in our MI models, we included auxiliary variables that were not part of the analytical model when imputing data. Thus, these models also followed current recommendations of following an inclusive analysis strategy (Enders, 2010). MI generates multiple copies of the data set, and each contains different estimates of missing values. We used Mplus MI procedure to generate 125 data sets. We then ran models within Mplus where analyses are conducted for all imputations separately and a summary of results are provided. With one reservation (the effect of early breadth on academic self-concept linear slope was only $\mathrm{p}=.05)$, results were all substantively the same. Particularly for small-sized effects, MI tends to be under-powered relative to FIML, and this likely explains the anomaly (Graham, Olchowski, \& Gilreath, 2007).

Multivariate Models, SES Invariance Testing.

Quadratic variances constrained to zero to facilitate model convergence.

General Self-Concept: Intercept correlations, linear slope correlations, \& quadratic slope correlations in multivariate model constrained vs. free for high vs low SES: $\chi^{2}(6)=8.77$, ns.

Academic Self-Concept: Intercept correlations, linear slope correlations, \& quadratic slope correlations in multivariate model constrained vs. free for high vs low SESs: $\chi^{2}(6)=9.72$, ns.

Social Self-Concept: Intercept correlations, linear slope correlations, \& quadratic slope correlations in multivariate model constrained vs. free for high vs low SES: $\chi^{2}(6)=7.09$, ns.

Univariate Models, SES Invariance Testing.

General Self-Concept: Covariance structure constrained vs. unconstrained for high vs. low SES: $\chi^{2}(6)=11.83, \mathrm{~ns}$.

Academic Self-Concept: Covariance structure constrained vs. unconstrained for high vs. low SES: $\chi^{2}(6)=8.30, n s$.

Social Self-Concept: covariance structure constrained vs. unconstrained for high vs low SES: $\chi^{2}$ $(6)=16.41, p=.01$. 
Higher SES intercept $=4.75(.04), \mathrm{p}<.001$; linear slope $=-.05(.04) \mathrm{ns}$; quadratic slope $=.01(.01)$ $=$ ns.

Higher SES intercept, linear slope correlation $=.18$, ns; intercept, quadratic slope $\mathrm{r}=-.24$, ns; linear, quadratic slope $\mathrm{r}=-.85, \mathrm{p}<.001$.

Lower SES intercept $=4.59(.05), \mathrm{p}<.001 ;$ linear slope $=-.19(.04), \mathrm{p}<.001 ;$ quadratic slope $=$ $.03(.01), \mathrm{p}=.008$.

Lower SES intercept, linear slope correlation $r=-.30$, ns; intercept, quadratic slope $r=.15$, ns; linear, quadratic slope $\mathrm{r}=-.92, \mathrm{p}<.001$.

For social self-concept, lower SES youth showed significant reductions in the early high school years, followed by significant increases later on. Higher SES youth, on the other hand, started slightly higher in social self-concept, and did not undergo significant linear or quadratic change in their social self-concept over time.

Breadth: Covariance structure constrained vs. unconstrained for high vs. low SES: $\chi 2(6)=$ $15.55, \mathrm{p}=.016$.

Higher SES intercept $=1.85(.05), \mathrm{p}<.001$; linear slope $=-.03(.04)$, ns; quadratic slope $=-$ $.03(.01), \mathrm{p}=.001$.

Higher SES intercept, linear slope correlation $r=.03$, ns; intercept, quadratic slope $r=-.33$, ns; linear, quadratic slope $\mathrm{r}=-.72, \mathrm{p}=.005$.

Lower SES intercept $=1.32(.04), \mathrm{p}<.001$; linear slope $=-.05(.04) \mathrm{ns} ;$ quadratic slope $=-$ $.01(.01)=\mathrm{ns}$.

Lower SES intercept, linear slope correlation $=.45$, ns; intercept, quadratic slope $\mathrm{r}=-.58$, ns; linear, quadratic slope $r=-.81, \mathrm{p}<.001$.

For breadth, higher SES youth engaged in a wider variety of activities in eighth grade, and showed less steep declines in the later high school years; whereas lower SES youth started lower in breadth (narrower participation breadth), and showed more rapid reductions in breadth later on (quadratic slope).

Intensity: Covariance structure constrained vs. unconstrained for high vs. low SES: $\chi^{2}(6)=$ 12.52, ns.

Multivariate Models, Gender Invariance Testing.

General Self-Concept: Intercept correlations, linear slope correlations, \& quadratic slope correlations in multivariate model constrained vs. free for females and males: $\chi^{2}(9)=10.52, n s$. 
Academic Self-Concept: Intercept correlations, linear slope correlations, \& quadratic slope correlations in multivariate model constrained vs. free for females and males: $\chi^{2}(9)=6.991, n s$.

Social Self-Concept: Intercept correlations, linear slope correlations, \& quadratic slope correlations in multivariate model constrained vs. free for females and males: $\chi^{2}(9)=14.98, n s$.

Univariate Models, Gender Invariance Testing.-check that this is correct with degrees of freedom.

General Self-Concept: Covariance structure constrained vs. unconstrained for females and males: $\chi^{2}$ (6) 10.01 , ns.

Academic Self-Concept: Covariance structure constrained vs. unconstrained for females and males: $\chi^{2}(6)=7.42, n s$.

Social Self-Concept: Covariance structure constrained vs. unconstrained for females and males, quadratic variance constrained to zero to facilitate model convergence: $\chi^{2}$ (3) $17.63, p<.001$.

Female intercept $=4.75(.04), \mathrm{p}<.001 ;$ linear slope $=-.15(.04), \mathrm{p}<.001 ;$ quadratic slope $=.018$ (.01), $\mathrm{p}=.022$.

Female intercept, linear slope correlation $=-.21, \mathrm{p}=.034$

Male intercept $=4.56(.05), \mathrm{p}<.001 ;$ linear slope $=-.08(.04), \mathrm{p}=.06 ;$ quadratic slope $=.02(.01)$, $\mathrm{p}=.132$.

Make intercept, linear slope correlation $=-.4, \mathrm{p}<.001$

For social self-concept, females showed significant reductions in the early high school years, followed by significant increases later on. Males, on the other hand, showed only trend-level reductions in the early high-school years.

Breadth: Covariance structure constrained vs. unconstrained for females and males; quadratic variances constrained to zero to facilitate model convergence: $\chi^{2}$ (3) $2.85=n s$.

Intensity: Covariance structure constrained vs. unconstrained for females and males; quadratic variances constrained to zero to facilitate model convergence $: \chi^{2}(3) 16.14 ; p=.001$.

Female intercept $=8.58(.32), \mathrm{p}<.001 ;$ linear slope $=1.13(.28), \mathrm{p}<.001 ;$ quadratic slope $=-.41$ (.07), $\mathrm{p}<.001$.

Female intercept, linear slope correlation $=-.27, \mathrm{p}=.012$.

Male intercept $=10.25(.39), \mathrm{p}<.001 ;$ linear slope $=1.72(.33), \mathrm{p}<.001 ;$ quadratic slope $=-.58$ (.08), $\mathrm{p}<.001$. 
Male intercept, linear slope correlation $=-.14$, ns.

For intensity, males started higher in hours per week than females, and increased in intensity at a faster rate during the early high school years, decreasing at a faster rate later on. There was a stronger link between grade 8 intensity and change in ECA for females than for males.

Auto-Regressive Cross- Lag Panel Models.

\section{General Self-Worth:}

As described in Figure S2, the cross-lag model had generally poor fit. That said, findings generally align with results of our multivariate parallel process model. These indicate that early breadth, at waves 1 and 2, predicted subsequent higher general self-worth at waves 2 and 3, respectively. ECA hours was only related to general self-worth at wave 3, prospectively predicting wave 4 general self-worth. Although neither breadth nor intensity predicted subsequent general self-concept at wave 5, breadth and general self-concept (but not intensity and self-concept) were correlated at the final wave.

\section{Academic Self-Concept:}

As described in Figure S3, the cross-lag model again had generally poor fit. Again, however, findings generally align with results of our multivariate parallel process model. Cross-lag results show that breadth at waves 1,2 , and 3 prospectively predicted higher academic self-concept at subsequent waves. Breadth did not predict academic self-concept at the final wave (wave 5), and ECA intensity was not related to subsequent academic self-concept at any wave.

\section{Social Self-Concept:}

As shown in Figure S4, the social self-concept cross-lag model also had poor fit. Results were substantively similar to those of our multivariate process models, however. Wave 2 breadth predicted wave 3 social self-concept. Intensity was not related to subsequent social self-concept at any wave. 


\section{References}

Blomfield, C. J. \& Barber, B. L. (2009). Performing on the stage, the field, or both?

Extracurricular activity participation and Australian adolescent self-concept. Journal of

Adolescence, 32, 733-739. doi: 10.1016/j.adolescence.2009.01.003

Enders, C. K. (2010). Applied Missing Data Analysis. New York: The Guildford Press.

Graham, J. W., Olchowski, A. E., \& Gilreath, T. D. (2007). How many imputations are really needed? Some practical clarifications of multiple imputation theory. Prevention Science, 8, 206213.

Harden, K. P., Turkheimer, E., Emery, R. E., D'Onofrio, B. M., Slutske, W. S., Heath, A. C., \& Martin, N. G. (2007). Marital conflict and conduct problems in children of twins. Child Development, 78(1), 1-18.

Miller, R. B., \& Wright, D. W. (1995). Detecting and correcting attrition bias in longitudinal family research. Journal of Marriage and the Family, 921-929.

Modecki, K. L., Barber, B. L., \& Vernon, L. (2013). Mapping developmental precursors of cyber-aggression: Trajectories of risk predict perpetration and victimization. Journal of Youth and Adolescence, 42(5), 651-661.

Muthén, L. K. \& Muthén, B. FIML vs. MI (2011) [online comment]. Retrieved from http://www.statmodel.com/discussion/messages/22/2440.html?1425099486 
Vernon, L., Modecki, K. L., \& Barber, B. L. (2017). Mobile Phones in the Bedroom: Trajectories of Sleep Habits and Subsequent Adolescent Psychosocial Development. Child Development.

Yuan, K., \& Bentler, P. M. (2000). Three likelihood-based methods for mean and covariance structure analysis with nonnormal missing data. Sociological Methodology, 30, 165-

200. doi: 10.1111/0081-1750.0007 
Table S1. Correlations between breadth of participation and extracurricular portfolio at each wave.

\section{Extracurricular Portfolio}

\section{Portfolio W1 Portfolio W2 Portfolio W3 Portfolio W4 Portfolio W5}

\begin{tabular}{lccccc}
\hline Breadth & \multicolumn{7}{l}{} \\
Breadth W1 & .76 & .39 & .35 & .32 & .23 \\
Breadth W2 & .37 & .73 & .421 & .37 & .21 \\
Breadth W3 & .38 & .44 & .76 & .45 & .27 \\
Breadth W4 & .30 & .36 & .43 & .78 & .41 \\
Breadth W4 & .21 & .20 & .26 & .40 & .77 \\
\hline
\end{tabular}

Note. Portfolio = 1 = sport only, 2 = activity only, $3=$ both sport and non-sport activity; see Blomfield \& Barber, 2009.

All correlations significant at $p<.01$. 
Table S2. Percentage of youth participating in sport and non-sport activities at each wave.

\section{Extracurricular Portfolio}

$$
\text { Sport only Activity only Both sport and activity }
$$

\begin{tabular}{llll}
\hline Wave & & & \\
1 & $35.0 \%$ & $10.7 \%$ & $47.5 \%$ \\
2 & $35.8 \%$ & $13.5 \%$ & $43.7 \%$ \\
3 & $35.8 \%$ & $15.2 \%$ & $40.9 \%$ \\
4 & $34.3 \%$ & $17 \%$ & $32.5 \%$ \\
5 & $33.5 \%$ & $17.8 \%$ & $26.4 \%$ \\
\hline
\end{tabular}


Table S3. Illustrative activities within each activity-type.

\begin{tabular}{|c|c|c|c|c|c|}
\hline \multicolumn{6}{|c|}{ Activity Type } \\
\hline Sports & Performance/Fine Art & Academic Clubs & Recreation Club & Service & Faith-Based Club \\
\hline Field-hockey & Community band & Chess club & Computer gaming & Cadets & Church groups \\
\hline Cricket & Community orchestra & Debate club & Computer networking & Scouts & Youth groups \\
\hline Basketball & Drama club & Language club & & Army Reserve & \\
\hline Football (AFL) & Dance Club & Public Speaking & & & \\
\hline \multicolumn{6}{|l|}{ Rugby } \\
\hline \multicolumn{6}{|l|}{ Volleyball } \\
\hline \multicolumn{6}{|l|}{ Tennis } \\
\hline \multicolumn{6}{|l|}{ Swimming } \\
\hline \multicolumn{6}{|l|}{ Water polo } \\
\hline \multicolumn{6}{|l|}{ Netball } \\
\hline \multicolumn{6}{|l|}{ Soccer } \\
\hline Cross-country & & & & & \\
\hline
\end{tabular}


Table S4. Univariate unconditional model fit indices for growth curves of self-concept and ECA breadth.

\section{Model Fit Indices}

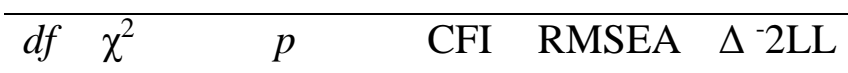

General self-worth

$\begin{array}{llllll}\text { 1. Linear model } & 10 & 53.79 & .000 & .953 & .058\end{array}$

$\begin{array}{llllllll}\text { 2. Quadratic model } & 6 & 5.27 & .509 & 1.00 & .000 & 48.83^{* * * *}\end{array}$

Social self-concept

$\begin{array}{llllll}\text { 1. Linear model } & 10 & 30.42 & .001 & .978 & .039\end{array}$

$\begin{array}{lllllll}\text { 2. Quadratic model } & 6 & 9.89 & .129 & .996 & .022 & 19.53^{* * *}\end{array}$

Academic self-concept

$\begin{array}{llllll}\text { 1. Linear model } & 10 & 57.55 & .000 & .950 & .060\end{array}$

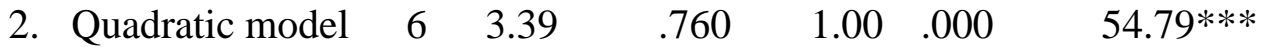

ECA breadth

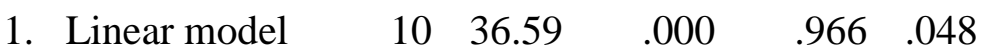

$\begin{array}{llllllll}2 . & \text { Quadratic model } & 6 & 11.32 & .08 & .996 & .028 & 27.67^{* * *}\end{array}$

ECA intensity

$\begin{array}{llllll}\text { 1. Linear model } & 14 & 163.60 & .000 & .831 & .097\end{array}$

2. Quadratic model $\quad \begin{array}{llllll}10 & 46.49 & .000 & .959 & .056 & 119.78^{* * * *}\end{array}$

Note: $* * * p<.001$ 
Table S5.

Factor regression coefficients and correlation coefficients from ECA intensity parallel process models.

\begin{tabular}{|c|c|c|c|}
\hline & \multicolumn{3}{|c|}{ ECA Intensity } \\
\hline & Intercept & Linear Slope & Quadratic Slope \\
\hline \multicolumn{4}{|l|}{ General Self-Worth } \\
\hline Intercept & $.44(.16) .21 * *$ & $1.35(.80) .31^{+}$ & $-.41(.21)-.37^{+}$ \\
\hline Linear Slope & $.01(.01) .10$ & $.20(.20) .15$ & \\
\hline Quadratic Slope & $-.00(.00)-.14$ & & $.01(.01) .16$ \\
\hline \multicolumn{4}{|l|}{ Social Self-Concept } \\
\hline Intercept & $.43(.18) .18 *$ & $.78(.69) .18$ & $-.25(.18)-.22$ \\
\hline Linear Slope & $.00(.01) .02$ & $.28(.21) .21$ & \\
\hline Quadratic Slope & $.00(.00)-.02$ & & $.02(.01) .18$ \\
\hline \multicolumn{4}{|c|}{ Academic Self-Concept } \\
\hline Intercept & $.24(.19) .09$ & $.31(.58) .07$ & $-.11(.15)-.10$ \\
\hline Linear Slope & $.01(.01) .06$ & $.34(.22) .25$ & \\
\hline Quadratic Slope & $-.00(.00)-.09$ & & $.02(.01) .22$ \\
\hline
\end{tabular}

Note. All models include gender, SES, ethnicity, early depressed mood, and early self-esteem as time-invariant covariates. Standardized coefficients in bold; significance for unstandardized coefficients. Standardized values are correlation coefficients for correlated intercepts, linear, and quadratic slopes. Values are regression coefficients for slopes regressed on intercepts.

${ }^{+} p<.10, * p<.05, * * p<.01$. 
Table S6.

Factor regression coefficients and correlation coefficients for ECA breadth parallel process models.

\section{ECA Breadth}

Intercept Linear Slope Quadratic Slope

\section{General Self-Worth}

Intercept

$.04(.02) .18 *$

.03 (.10) $.63 \quad-.01(.03)-.07$

Linear Slope

$.24(.07) .31 * *$

$.01(.02) .09$

Quadratic Slope

$-.06(.02)-.33 * *$

$.00(.00) \quad .14$

\section{Social Self-Concept}

Intercept

Linear Slope

Quadratic Slope
$-.03(.08)-.11$

$.14(.08) .20^{+}$

$-.02(.02)-.15$

\section{Academic Self-Concept}

$$
\text { Intercept }
$$

Linear Slope

Quadratic Slope

$$
.08(.03) .25 * *
$$$$
.17(.08) .25 *
$$$$
-.05(.02)-.30 *
$$

$\begin{array}{ll}.02(.08) .05 & .01(.02) .02\end{array}$

$.03(.02) .21$

$$
.00(.00) .19
$$

Note. All models include gender, SES, ethnicity, early depressed mood, and early self-esteem as time-invariant covariates. Standardized coefficients in bold; significance for unstandardized coefficients. Standardized values are correlation coefficients for correlated intercepts, linear, and quadratic slopes. Values are regression coefficients for slopes regressed on intercepts. $* p<.05, * * p<.01$. 
Figure S1.

Schematic Representation of Multivariate Growth Curves of Self-Concept, ECA Breadth, and ECA Intensity.

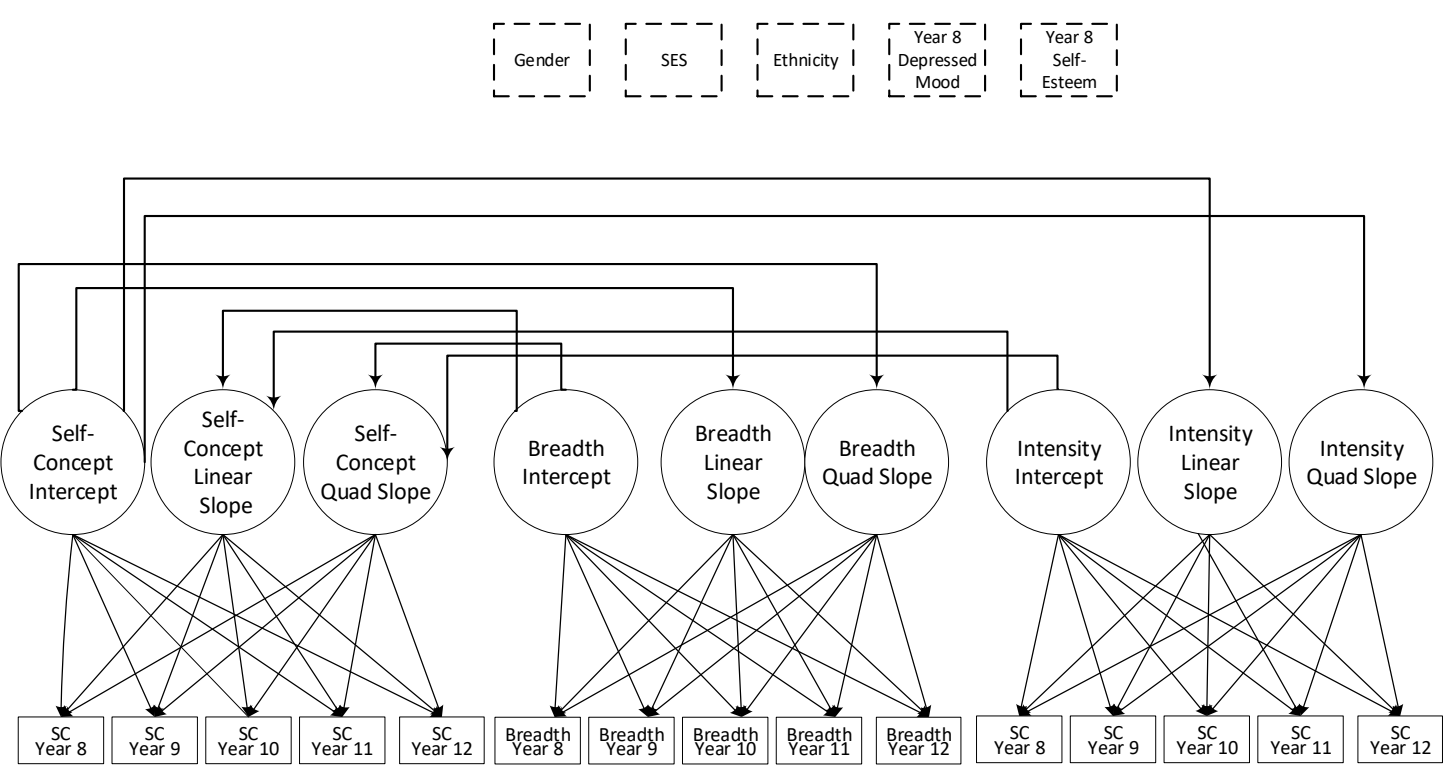

Note. Covariances between intercepts, linear slopes, and quadratic slopes not shown. Residual covariances between intensity and breadth at each time point not shown. The following also not shown: Breadth linear and quadratic slopes regressed on intensity intercept. Intensity linear and quadratic slopes regressed on breadth intercept. Intercepts, linear slopes, and quadratic slopes of self-concept, ECA breadth, and ECA intensity regressed on Gender, SES, ethnicity, early depressed mood and selfesteem. 
Figure S2. Auto-regressive cross-lag panel models for general self-worth.

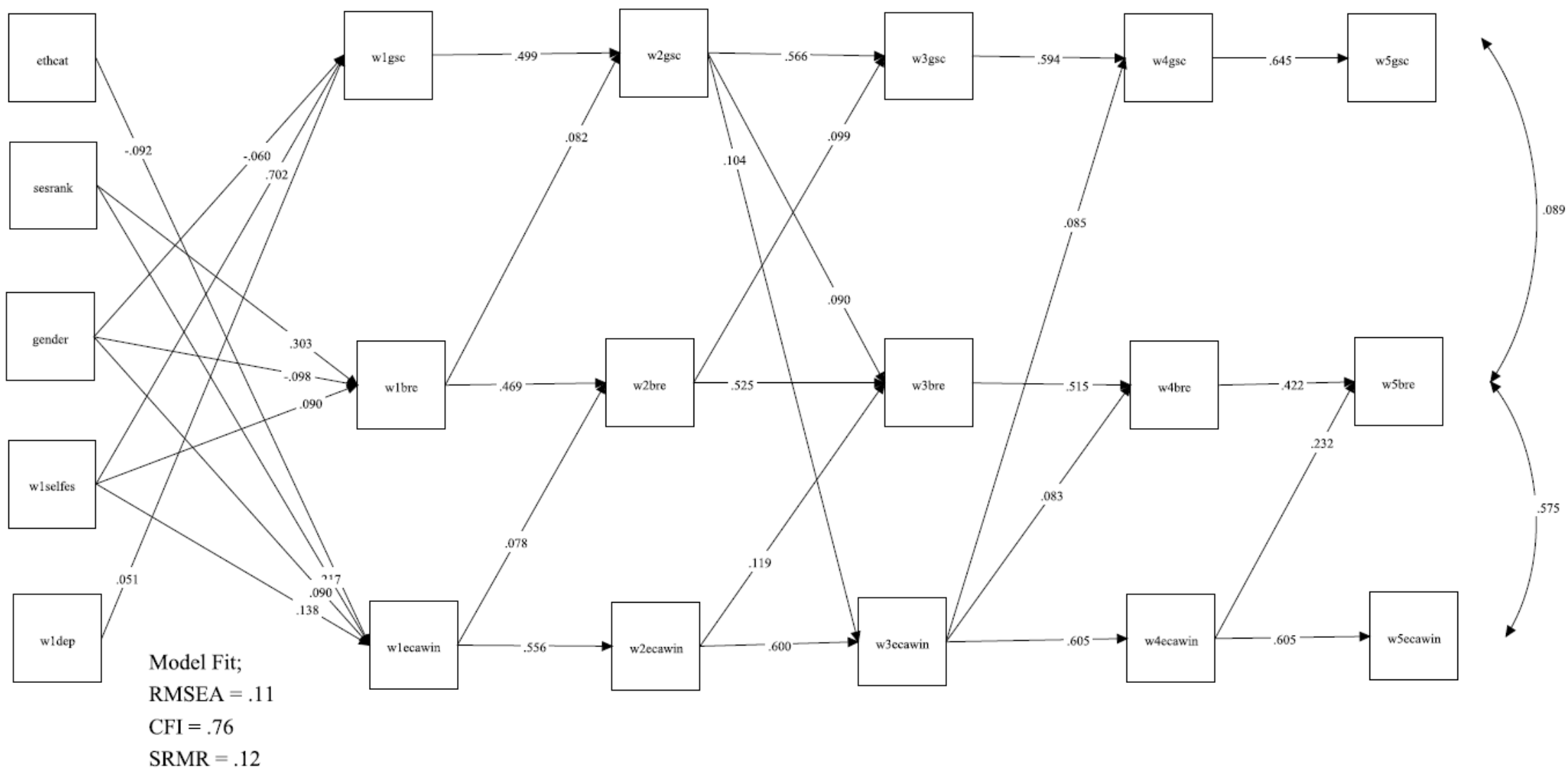

Note. Standardized estimates; only significant paths shown. GSC $=$ general self-worth; BRE = breadth; ECAWIN $=$ ECA intensity. 
Figure S3. Auto-regressive cross-lag panel models for academic self-concept.

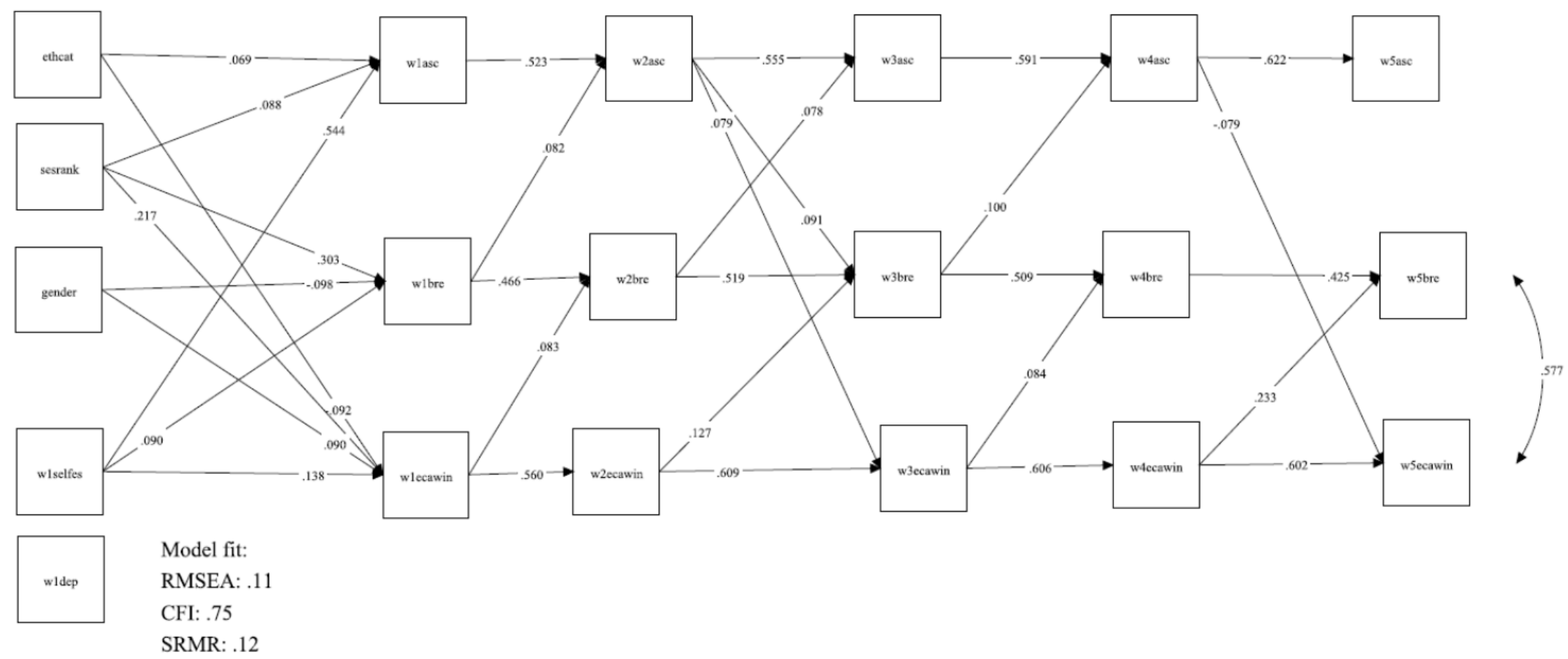

Note. Standardized estimates; only significant paths shown. $\mathrm{SSC}=$ social self-concept; BRE $=$ breadth; ECAWIN $=\mathrm{ECA}$ intensity. 
Figure S4. Auto-regressive cross-lag panel models for social self-concept.

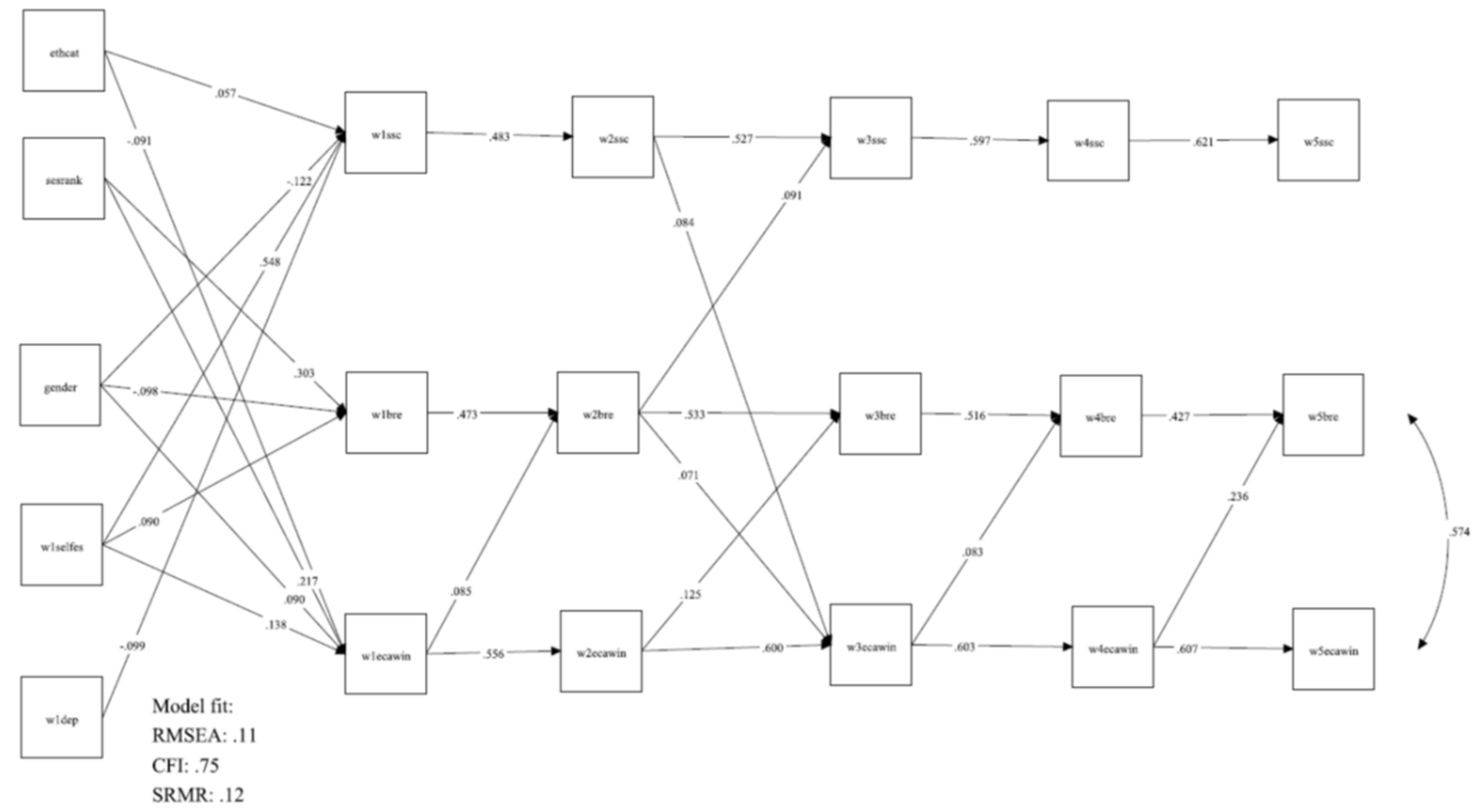

Note. Note. Standardized estimates; only significant paths shown. ASC = academic self-concept; BRE = breadth; ECAWIN = ECA intensity . 